NBER WORKING PAPER SERIES

MPCS, MPES AND MULTIPLIERS:

A TRILEMMA FOR NEW KEYNESIAN MODELS

\author{
Adrien Auclert \\ Bence Bardóczy \\ Matthew Rognlie \\ Working Paper 27486 \\ http://www.nber.org/papers/w27486 \\ NATIONAL BUREAU OF ECONOMIC RESEARCH \\ 1050 Massachusetts Avenue \\ Cambridge, MA 02138 \\ July 2020, Revised March 2021
}

An earlier version of this paper circulated under the title "A Note on Multipliers in NK Models with GHH Preferences". We thank the editors Yuriy Gorodnichenko and Olivier Coibion, three anonymous referees, as well as Florin Bilbiie, Gabriel Chodorow-Reich, Greg Kaplan, Alisdair McKay, Ben Moll, Krisztina Molnár, and Valerie Ramey for useful comments and suggestions. The views expressed herein are those of the authors and do not necessarily reflect the views of the National Bureau of Economic Research.

NBER working papers are circulated for discussion and comment purposes. They have not been peer-reviewed or been subject to the review by the NBER Board of Directors that accompanies official NBER publications.

(C) 2020 by Adrien Auclert, Bence Bardóczy, and Matthew Rognlie. All rights reserved. Short sections of text, not to exceed two paragraphs, may be quoted without explicit permission provided that full credit, including $(\odot$ notice, is given to the source. 
MPCs, MPEs and Multipliers: A Trilemma for New Keynesian Models

Adrien Auclert, Bence Bardóczy, and Matthew Rognlie

NBER Working Paper No. 27486

July 2020, Revised March 2021

JEL No. D52,E52,E62,H31

\section{ABSTRACT}

We show that New Keynesian models with frictionless labor supply face a challenge: given standard parameters, they cannot simultaneously match plausible estimates of marginal propensities to consume (MPCs), marginal propensities to earn (MPEs), and fiscal multipliers. A HANK model with sticky wages provides a solution to this trilemma.

Adrien Auclert

Department of Economics

Stanford University

579 Serra Mall

Stanford, CA 94305-6072

and NBER

aauclert@stanford.edu

Bence Bardóczy

Northwestern University

Department of Economics

2211 Campus Drive

Evanston, IL 60208

bardoczy@u.northwestern.edu
Matthew Rognlie

Department of Economics

Northwestern University

2211 Campus Drive

Evanston, IL 60208

and NBER

matthew.rognlie@northwestern.edu 


\title{
MPCs, MPEs and Multipliers: A Trilemma for New Keynesian Models
}

Adrien Auclert*

\author{
Matthew Rognlie $\ddagger$
}

\author{
March 2021
}

\begin{abstract}
We show that New Keynesian models with frictionless labor supply face a challenge: given standard parameters, they cannot simultaneously match plausible estimates of marginal propensities to consume (MPCs), marginal propensities to earn (MPEs), and fiscal multipliers. A HANK model with sticky wages provides a solution to this trilemma.
\end{abstract}

\section{Introduction}

In recent decades, macroeconomics has experienced a micro-moment revolution. As the field has recognized the importance of heterogeneity for macroeconomic outcomes, it has increasingly used estimates from disaggregated data to discipline its models.

One moment that epitomizes this revolution is the marginal propensity to consume (MPC): the amount by which consumption increases in response to a one-time transitory increase in income. Recent research has established that MPCs are extremely important for the macroeconomic effects of shocks and policy, both in partial equilibrium (e.g. Kaplan and Violante 2014, Auclert 2019, Berger, Guerrieri, Lorenzoni and Vavra 2018) and in general equilibrium (e.g. Kaplan, Moll and Violante 2018, Auclert, Rognlie and Straub 2018). Moreover, there exists a widespread consensus on the average level of MPCs in the data. We summarize this consensus as:

Fact 1. Average MPCs are high in the data, around 0.25 quarterly and 0.5 annually.

\footnotetext{
*Stanford University, CEPR and NBER. Email: aauclert@stanford.edu.

${ }^{\dagger}$ Northwestern University. Email: bardoczy@u.northwestern.edu.

†Northwestern University and NBER. Email: matthew.rognlie@northwestern.edu. An earlier version of this paper circulated under the title "A Note on Multipliers in NK Models with GHH Preferences". We thank the editors Yuriy Gorodnichenko and Olivier Coibion, three anonymous referees, as well as Florin Bilbiie, Gabriel Chodorow-Reich, Greg Kaplan, Alisdair McKay, Ben Moll, Krisztina Molnár, and Valerie Ramey for useful comments and suggestions.
} 
As is widely recognized in the literature, Fact 1 is important because it disqualifies almost all standard representative-agent models, which are based on the permanent-income hypothesis and therefore generate low average MPCs. Instead, Fact 1 favors models with heterogeneous agents and incomplete markets.

In standard macroeconomic models, agents have two immediate margins of adjustment when they receive a one-time income shock: they can consume more or work less (the rest is saved). The MPC measures how much they increase their consumption. The marginal propensity to earn, or MPE, measures how much they reduce their earned income. While the MPE has received somewhat less attention in the macroeconomic literature, it is the labor market equivalent of the MPC. As such, it is in principle equally important for macroeconomic adjustment, and constitutes an equally natural target for calibrating models with heterogeneous agents. Moreover, there also exists a literature estimating MPEs in micro data. We summarize the evidence on the average level of MPEs in that literature as:

Fact 2. Average MPEs are small in the data, around 0 to 0.04 annually.

The combination of Facts 1 and 2 poses a challenge for heterogeneous agent models with a flexible labor supply choice. Under separable preferences, unless utility has very different curvatures in consumption and labor, agents that are free to adjust their labor supply should adjust to income transfers on the consumption and the labor supply margins by comparable amounts. If average MPCs are high, then average MPEs should be high as well.

The standard solution to this challenge is to consider alternative preference specifications that dampen wealth effects on labor supply, such as GHH preferences (Greenwood, Hercowitz and Huffman 1988). As we prove formally in this paper, any preference specification that lowers wealth effects must also increase the degree of complementarity between consumption and labor in preferences. While there is empirical support for some complementarity between consumption and labor (e.g. Aguiar and Hurst 2013), in this paper we show that too much complementarity poses a critical third challenge for business cycle models.

To understand this challenge, keep in mind that the micro-moment revolution should not eclipse the long tradition of disciplining macro models with macro moments. In this paper, we will focus on one particular conditional macro moment: the fiscal multiplier, i.e. the effect of government spending on aggregate output. There is a long empirical tradition of estimating the fiscal multiplier in aggregate time-series data, and of using it to gauge the plausibility of business cycle models. ${ }^{1}$ We summarize the consensus evidence in that literature as:

Fact 3. Fiscal multipliers lie in a moderate range in the data. Under accommodative monetary policy, both impact and cumulative multipliers are between 0.6 and 2.

The most common framework for studying these multipliers is the New Keynesian model with a frictionless labor market, featuring sticky prices and flexible wages. As Monacelli and Perotti

\footnotetext{
${ }^{1}$ For example, following Galí, López-Salido and Vallés (2007), the positive response of consumption to government purchases in structural VARs has motivated a very large literature searching for models that can deliver this feature. Monetary policy shocks provide alternative conditional moments to discipline business cycle models.
} 


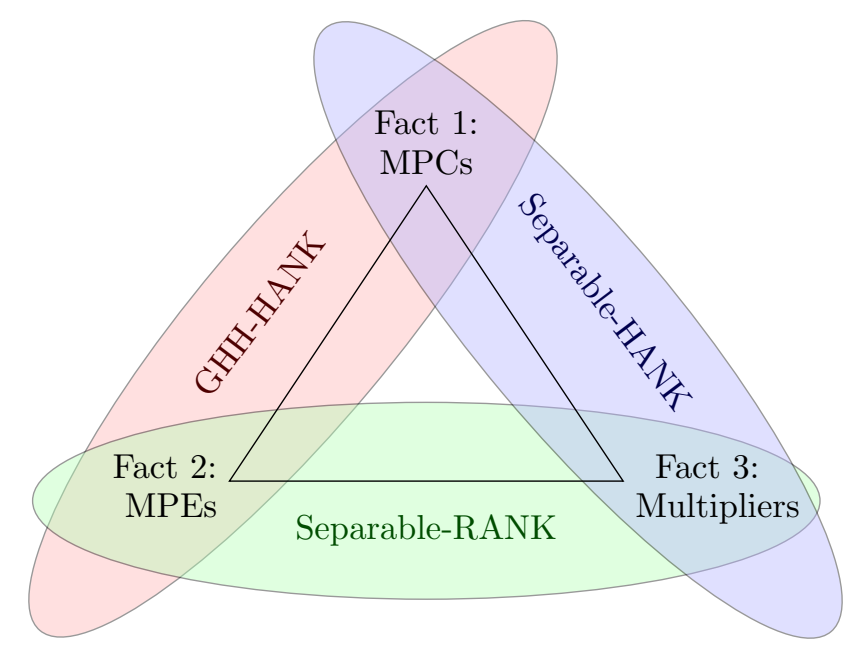

Figure 1: The trilemma

(2008) and Bilbiie (2011) have pointed out, introducing consumption-labor complementarity into this model leads to higher multipliers under accommodative policy. Building on their findings, we argue that when there is enough complementarity in the model to reconcile Facts 1 and 2, the resulting multiplier is high enough to violate Fact 3. This creates a trilemma for New Keynesian models with frictionless labor supply: it is impossible with standard calibrations to simultaneously match Facts 1, 2, and 3.

Figure 1 provides a graphical summary of this trilemma: it is possible to match any two of the three facts, but only at the cost of missing the third. First, with standard separable preferences, a heterogeneous-agent New Keynesian ("HANK") model with sticky prices and flexible wages can match MPCs and multipliers. ${ }^{2}$ But this generates average MPEs that are much higher than in the data. For example, when we calibrate such a heterogeneous-agent model to feature a quarterly MPC of 0.25 , the annual MPE is over 0.2-at least five times as large as the data. Alternatively, GHH preferences shut off wealth effects on labor supply, so that all agents have an MPE of 0 . This allows a HANK model to match MPCs and MPEs simultaneously, ${ }^{3}$ but at the cost of generating very high fiscal multipliers: our calibration implies an impact multiplier above 3, and a cumulative multiplier around 5.5. Finally, a representative-agent New Keynesian ("RANK") model with separable preferences can match fiscal multipliers and MPEs, but misses MPCs.

We establish the trilemma in two steps. First, we use consumer theory to show that, at the microeconomic level, MPCs and MPEs are related by a "complementarity index" (CI) that measures the strength of the complementarity between consumption and labor supply. Taking the elasticity of intertemporal substitution and the Frisch elasticity as given, lowering MPEs relative

\footnotetext{
${ }^{2}$ See McKay, Nakamura and Steinsson (2016) and Kaplan, Moll and Violante (2018) for prominent versions of such a model. There is also an earlier two-agent New Keynesian literature that uses higher MPCs to generate higher multipliers, including Galí et al. (2007) and Bilbiie and Straub (2004).

${ }^{3}$ This route is taken, for instance, by Bayer, Luetticke, Pham-Dao and Tjaden (2019), and was also taken by the original versions of Kaplan, Moll and Violante (2018) and Auclert (2019).
} 
to MPCs requires raising CI: it is not possible to limit the wealth effect on labor supply without simultaneously raising the degree of complementarity between consumption and labor.

Second, using a combination of analytical results and numerical simulations, we show that it is the same complementarity index that, in New Keynesian models, regulates the size of the fiscal multiplier. The intuition is as follows. As a fiscal shock increases demand for output, wages must rise until enough labor is supplied in equilibrium to produce that output. When CI is positive, as households work more, they also want to consume more, and this additional consumption increases demand for output even further-prompting another increase in labor effort, and so on. The larger CI, the stronger this effect, and therefore the larger the multiplier. This explains the trilemma: the same force that reconciles Facts 1 and 2 makes it difficult to match Fact 3.

To cleanly isolate the importance of $\mathrm{CI}$ for the fiscal multiplier, we start by considering the representative-agent case. There, we show that the multiplier, if monetary policy maintains a constant real interest rate, is given by

$$
\frac{d Y_{t}}{d G_{s}}=\frac{1}{1-(1-\tau) C I} \cdot \mathbf{1}_{s=t}
$$

where $\tau<1$ is the labor wedge. When preferences are separable, CI is 0 , and one dollar of government spending increases output in the same period by one dollar: the constant- $r$ fiscal multiplier is 1. This is the celebrated result from Woodford (2011). Under GHH preferences, CI is 1 , and the constant- $r$ fiscal multiplier is $\frac{1}{\tau}$. In standard parameterizations of the New Keynesian model, $\frac{1}{\tau}$ equals the elasticity of substitution between varieties $\epsilon_{p}$, which is usually calibrated to be at least 5 . This implies an equally high multiplier, far outside the range of Fact 3.

A sharp analytical result such as equation (1) cannot be obtained for general HANK models, which must be solved numerically. We therefore set up a quantitative HANK model with preferences that can generate an arbitrary complementarity index, and demonstrate that there does not exist any level of CI that can quantitatively reconcile Facts 1, 2 and 3. Specifically, we introduce preferences that we call "GHH-plus". These preferences span separable, GHH, and a continuum of cases in between, controlled by a single additional parameter $\alpha \in[0,1] .{ }^{4}$ For each $\alpha$, we calibrate the model to hit an quarterly average MPC of 0.25 , so that our model matches Fact 1 by construction. We then calculate the average MPEs and the fiscal multipliers that result from this parameterization. We show that there is no value of $\alpha$ that can also simultaneously hit Facts 2 and 3. This is the trilemma. We show that varying parameters in particular directions-for instance, assuming a much lower Frisch elasticity — can relax the trilemma, bringing intermediate- $\alpha$ calibrations closer to an acceptable fit, but does not provide a robust solution.

The trilemma can be solved by introducing labor market frictions into a HANK model with separable preferences. In this paper, we do so via sticky wages and demand-determined labor. An alternative and arguably better-microfounded approach would be to introduce search frictions in

\footnotetext{
${ }^{4}$ As we discuss in section 4.1, our preference specification is related to, but different from, Bilbiie (2020), who also introduces a specification that embeds separable and GHH preferences.
} 
the labor market, as in Gornemann, Kuester and Nakajima (2016) or Ravn and Sterk (2017). ${ }^{5}$ In all of these models, workers are off their labor supply curves in the short run, so their effective MPEs are near 0, consistent with Fact 2. It is then possible to simultaneously hit MPCs (Fact 1) and multipliers (Fact 3).

A few other papers have argued that HANK models with flexible wages are difficult to reconcile with the data. Broer, Hansen, Krusell and Öberg (2020) focus on the implied countercyclicality of profits. Nekarda and Ramey (2020) argue that the implied cyclicality of marginal costs is rejected by the data. We add the trilemma to these voices against the flexible-wage model. ${ }^{6}$

The organization of the paper is as follows. In section 1 we provide a review of the literature supporting Facts 1-3. In section 2, we establish the relationship between MPCs, MPEs and the complementarity index in a standard consumer theory model. In section 3 we establish the relationship between the complementarity index and fiscal multipliers in RANK models. Finally, in section 4 we set up a HANK model with general preferences and show that there is no parameterization that can simultaneously match Facts 1-3. We provide our sticky-wage solution to the trilemma in section 5. The appendix collects proofs, additional model details and results, and explains our computational approach.

\section{Evidence on MPCs, MPEs and multipliers}

We begin by reviewing the empirical evidence that underlies Facts 1-3.

MPCs. We define the MPC as the level of the response of spending to a one-time, unexpected unit payment, in the period of the payment, and averaged across individuals. For example, the unweighted quarterly MPC is the spending response in the quarter of the payment, uniformly weighted across individuals. The literature has argued that this is a critical moment for discriminating across models, and that, as such, it should be used to calibrate macroeconomic models of consumption behavior.

The empirical literature on MPCs is vast. Kaplan and Violante (2014) summarize this literature and perform some of their own analysis on the 2001 US tax rebates. They find that the "collective evidence convincingly concludes that households spend approximately 25 percent of rebates on nondurables in the quarter that they are received." Alternative studies support similar magnitudes with alternative methods, and for alternative sources of income. This leads us to Fact 1: the unweighted quarterly MPC is about 0.25 . We will calibrate our model, which has a quarterly frequency, to this target.

Some of the evidence on the MPC is at an annual frequency instead. The unweighted annual MPC in the literature is around 0.5. For example, the headline point estimate for the unweighted

\footnotetext{
${ }^{5}$ This does not work for every model with search frictions, however. If there is an elastic search effort margin or an elastic intensive margin, MPEs can be too high to match Fact 2.

${ }^{6}$ Accordingly, we welcome the recent trend in the HANK literature of assuming sticky wages in addition to, or as a substitute for, sticky prices (e.g. Hagedorn, Manovskii and Mitman 2019, Alves, Kaplan, Moll and Violante 2020).
} 
annual MPC in Fagereng, Holm and Natvik (2020) is 0.52, and the unweighted annual MPC from Jappelli and Pistaferri (2014) is $0.48 .^{7}$

There also is some evidence on heterogeneity in MPCs, consistent with the predictions of standard heterogeneous-agent models. For example, in the papers discussed above, agents that have lower levels of liquid wealth or appear subject to financial constraints tend to have higher MPCs.

MPEs. We define the MPE as the negative of the level of the response of earned income to a onetime, unexpected unit payment, in the period of the payment, and averaged across individuals. Since the best estimates of MPEs require administrative earnings data that is only available annually, the MPE is often reported on an annual basis. While our definition makes the MPE the labor-market equivalent of the MPC, we note that this is a different concept from those often used in the labor literature. Therefore, there exist few credible, direct estimates of it.

The best available evidence comes from Cesarini, Lindqvist, Notowidigdo and Östling (2017), who measure the MPE out of small one-time lottery earnings in Sweden. Unlike most prior studies, they work with administrative earnings data, which mitigates measurement error and concerns about small samples and differential nonresponse. Moreover, they are able to control for the number of tickets bought, which makes the conditional random assignment assumption much more plausible. They report a precisely estimated MPE of 0.01 , with a $95 \%$ confidence interval from 0.005 to $0.015 .^{8}$

A more traditional approach is to measure the MPE out of permanent earnings changes, such as those caused by winning an annuity when playing the lottery. Classic papers in this literature, such as the widely cited Imbens, Rubin and Sacerdote (2001), calculate the MPE as the change in earned income divided by the flow annuity payment. Because this object ignores intertemporal considerations - in particular, the fact that transfers in other periods can cause labor supply to fall this period-it substantially overestimates the MPE as we define it. ${ }^{9}$

In particular, the headline MPEs from Imbens et al. (2001), which range from 0.048 to 0.122 , need to be adjusted downward. These measure the "MPE" out of a yearly payment from a 20-year annuity, while we are interested in the MPE from a one-time payment. The ratio between these two notions of MPE is model-dependent. In a permanent income model with no discounting and a unit interest rate, the Imbens et al. (2001) MPE would be 20 times higher than our MPE. As a lower bound on our MPE, therefore, we divide their lowest estimate by 20, which gives us 0.0024 , or essentially zero. In a model with credit-constrained households, however, the two definitions are closer. For this case, we use our calibrated heterogeneous-agent model section 4 , in which we

\footnotetext{
${ }^{7}$ While the former use evidence from actual spending responses (to lottery earnings), the latter use answers to hypothetical survey questions. Parker and Souleles (2019) have found that these two methods of eliciting the MPC tend to yield similar answers.

${ }^{8}$ The effect is persistent, so that the cumulative MPE is somewhat higher, at about 0.10 . That cumulative number is the counterpart of the cumulative MPC, which has been estimated to be near 1, e.g. in Fagereng et al. (2020).

${ }^{9}$ Yet another tradition in the labor literature is to define the MPE as a static object measuring how a one-time unexpected unit payment is split between consumption and earned income (e.g. Pencavel 1986). These estimates correspond to, in our definition, MPE/ (MPC + MPE)—a substantially larger number than the MPE we have defined.
} 


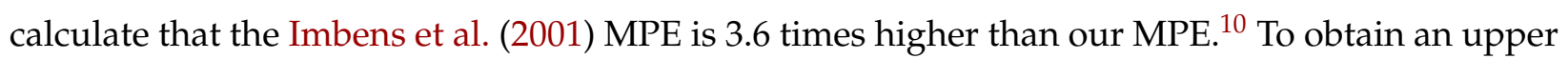
bound on our MPE, we then take their highest estimate and divide by 3.6, delivering 0.034 .

Combining this calculation with the Cesarini et al. (2017) results, and rounding up the upper bound, we formulate Fact 2 as: the annual MPE lies between 0 and 0.04 .

Fiscal multipliers. Fiscal multipliers summarize the macroeconomic impact of government spending on output. The impact fiscal multiplier is the response of GDP to a unit change in aggregate government spending. The cumulative fiscal multiplier is the present discounted value of the response of GDP to a unit change in the present discounted value of government spending. It is well known in the literature that fiscal multipliers depend on the response of monetary policy. The headline numbers we focus on to compare model and data are for a certain type of accommodative monetary policy that maintains constant real interest rates. As we show explicitly in section 4.5 , this type of monetary policy is less accommodative than the zero lower bound, but more accommodative than typical Taylor rules.

The empirical literature on fiscal multipliers is also vast. Ramey (2019) provides the most recent comprehensive review. She concludes that "the bulk of the estimates across the leading methods of estimation and samples lie in a surprisingly narrow range of 0.6 to 1 ", but that "The evidence for higher government spending multipliers during periods in which monetary policy is very accommodative, such as zero lower bound periods, is somewhat stronger. Recent time series estimates for the United States and Japan suggest that multipliers could be 1.5 or higher during those times." Ramey (2019) also makes a forceful argument that cumulative multipliers provide a more robust description of the data than impact multipliers (see also Mountford and Uhlig 2009). At times when policy is highly accommodative, Ramey (2011) suggests that "reasonable people" could defend an upper bound as high as 2.0. Overall, we take this summary of the evidence to support a range of fiscal multipliers between 0.6 to 2.0 when monetary policy is accommodative, for both impact and cumulative multipliers. This is our Fact 3.

\section{The MPC-MPE relationship}

We consider a heterogeneous-agent model with frictionless labor supply, as in e.g. Aiyagari and McGrattan (1998). Households face idiosyncratic risk to their productivity $e$, which follows an exogenous Markov chain. A household with current idiosyncratic productivity $e$ and assets $a$ at time $t$, when the ex-post real interest rate is $r_{t}$, the wage per efficiency unit is $w_{t}$, the wage tax is

\footnotetext{
${ }^{10}$ Specifically, we give agents in the separable heterogeneous-agent model of section 4 a 20 -year annuity, and calculate the ratio of their earnings response in the first year to the MPE out of a one-time payment, which we find to be 3.6.
} 
$\tau_{t}^{w}$, and transfers are $T_{t}$, solves

$$
\begin{aligned}
V_{t}(a, e)= & \max _{c, n, a^{\prime}} U(c, n)+\beta \mathbb{E}\left[V_{t+1}\left(a^{\prime}, e^{\prime}\right) \mid e\right] \\
\text { s.t. } & c+a^{\prime}=\left(1-\tau_{t}^{w}\right) w_{t} e n+T_{t}+\left(1+r_{t}\right) a \\
& a^{\prime} \geq \underline{a}
\end{aligned}
$$

This model is the backbone of a recent literature that incorporates heterogeneity into the equilibrium analysis of monetary and fiscal policy. It nests the representative-agent case, in which $e$ is a constant over time and $\underline{a}=-\infty$.

We allow for general $U(c, n)$ that satisfy standard conditions: continuous second derivatives, strict concavity, and Inada conditions that ensure an interior optimum. We will often refer to two particular cases. First, separable preferences take the form

$$
U(c, n)=u(c)-v(n)
$$

Second, following Greenwood et al. (1988), GHH preferences take the form

$$
U(c, n)=u(c-v(n))
$$

In the solution to the dynamic programming problem (2), agents are on a first-order condition for consumption vs. labor at all times, irrespective of whether they are currently at the borrowing constraint. Consider an agent in state $(a, e)$ facing the effective wage $\tilde{w} \equiv\left(1-\tau_{w}^{t}\right) w_{t} e$ and a multiplier of $\lambda=\lambda_{t}(a, e)$ on his budget constraint (2), and choosing the bundle $(c, n)$ of consumption and labor. This bundle must obey the first order conditions

$$
\begin{aligned}
& U_{c}(c, n)=\lambda \\
& U_{n}(c, n)=-\lambda \tilde{w}
\end{aligned}
$$

Let $c(\lambda, \tilde{w}), n(\lambda, \tilde{w})$ denote the solution to the system of equation (3) and (4). ${ }^{11}$ We define three preference parameters locally given $(\lambda, \tilde{w})$, which together fully characterize the second-order properties of the utility function. ${ }^{12}$ The elasticity of intertemporal substitution is defined in a standard way, as minus the elasticity of consumption to $\lambda$ at fixed wage,

$$
\mathrm{EIS} \equiv-\frac{\partial \log c(\lambda, \tilde{w})}{\partial \log \lambda}
$$

and the Frisch elasticity of labor supply is similarly defined as the elasticity of labor to the wage

\footnotetext{
${ }^{11}$ Given a solution for the multiplier $\lambda_{t}(a, e)$, the agent's policy functions for consumption and savings are then $c_{t}(a, e)=c\left(\lambda_{t}(a, e), w_{t}(e)\right)$ and $n_{t}(a, e)=n\left(\lambda_{t}(a, e), w_{t}(e)\right)$

${ }^{12}$ Since the Hessian of $U$ is symmetric, it only has 3 degrees of freedom.
} 
at fixed $\lambda$,

$$
\text { Frisch } \equiv \frac{\partial \log n(\lambda, \tilde{w})}{\partial \log \tilde{w}}
$$

We also introduce the complementarity index, or CI for short:

$$
\mathrm{CI} \equiv \frac{\partial c(\lambda, \tilde{w})}{\partial \tilde{w}} / \tilde{w} \frac{\partial n(\lambda, \tilde{w})}{\partial \tilde{w}}
$$

This is the marginal propensity to consume out of a change in earned income in response to $\tilde{w}$, holding $\lambda$ fixed. The following lemma establishes some facts about CI.

Lemma 1. For separable preferences, $C I=0$. For GHH preferences, $C I=1$. In general, $C I=\frac{U_{n c} / U_{n}}{U_{c c} / U_{c}}$.

For separable preferences, $C I=0$ because then $\lambda$ uniquely determines $c$ in (3). But when there is consumption-labor complementarity $U_{n c}>0$, then $\mathrm{CI}>0$ : higher labor effort $n$, holding $U_{c}=\lambda$ fixed, implies higher consumption $c$. The larger the response of $c$ to $n$, the higher the complementarity index.

For $\mathrm{GHH}$ preferences, it is not an accident that $\mathrm{CI}=1$. Lemma 1 shows that in general, $\mathrm{CI}$ is the ratio of the semielasticity of $U_{n}$ to $c$ and the semielasticity of $U_{c}$ to $c$. Since GHH preferences eliminate wealth effects on labor supply, a change in $c$ must increase $U_{n}$ and $U_{c}$ proportionally, so that the first-order condition $U_{n}=-\tilde{w} U_{c}$ is undisturbed. In other words, the two semielasticities must be equal, so that their ratio $\mathrm{CI}$ is 1 .

Now let us return to the more standard policy functions $c_{t}\left(a, e ; T_{t}\right)$ and $n_{t}\left(a, e ; T_{t}\right)$, making the dependence on the transfer $T_{t}$ explicit. The marginal propensity to consume out of a transfer is

$$
\mathrm{MPC} \equiv \frac{\partial c_{t}\left(a, e ; T_{t}\right)}{\partial T_{t}}
$$

and the marginal propensity to earn is

$$
\mathrm{MPE} \equiv-\tilde{w} \frac{\partial n_{t}\left(a, e ; T_{t}\right)}{\partial T_{t}}
$$

With these definitions in hand, we prove the following relationship.

Proposition 1. For any individual in state $(a, e)$ at time $t$, we have

$$
\frac{\mathrm{MPE}}{\mathrm{MPC}}=\frac{\tilde{w} n}{\mathrm{c}} \cdot \frac{\text { Frisch }}{\mathrm{EIS}} \cdot(1-\mathrm{CI})
$$

Equation (6) relates, at the individual level, the ratio of MPC and MPE to the earned-income-toconsumption ratio and the three preference parameters EIS, Frisch and CI. Note that both MPC and MPE are complicated objects that depend on both the idiosyncratic state $(a, e)$ and aggregate state $t$. But equation (6) shows that MPC is a sufficient statistic for MPE, and vice versa. The derivation of equation (6) requires only that conditions (3) and (4) be satisfied, so it characterizes behavior in a very broad class of models with flexible labor supply. 
To understand the quantitative implications of (6), consider that in typical calibrations, Frisch $\simeq$ EIS, and asset and transfer income are small, so that $c \simeq \tilde{w} n$ for most agents. This implies that for these agents,

$$
\mathrm{MPE} \simeq(1-\mathrm{CI}) \cdot \mathrm{MPC}
$$

Suppose first that preferences are separable, so that CI is 0. Equation (7) then implies that for most agents, MPC and MPE are approximately the same. For example, constrained agents that do not save should have an MPC of 0.5 and an MPE of 0.5. As discussed in section 1, while there is some evidence that constrained agents have a high MPC, there is no good evidence supporting this kind of large MPE. More generally, equation (7) shows that the average MPE and the average MPC should be about the same. Hence, if preferences are separable, Facts 1 and 2 cannot hold simultaneously.

Indeed, equation (7) suggests that matching both facts requires raising the complementarity index towards 1. For instance, taking an annual MPE of 0.04 from the upper bound of Fact 2 and an annual MPC of 0.50 from Fact 1 requires $\mathrm{CI}$ to be at least $1-0.04 / 0.50=0.92$. GHH preferences, with their $\mathrm{CI}$ of 1 , may therefore seem like a natural solution. Next we show that such high levels of CI create a challenge for Fact 3.

\section{Consumption-labor complementarity and fiscal multipliers}

In this section, we study a representative-agent model to gain insights into the relationship between CI and fiscal multipliers. While it is well known that the representative-agent model cannot match Fact 1, and is therefore not a candidate to solve the trilemma, the analytical formula we obtain from considering this case uncovers a force that is central in HANK models as well. Our result from this section complements existing results by Bilbiie (2011) and Monacelli and Perotti (2008) showing that consumption-labor complementarity can increase the fiscal multiplier in New Keynesian models. ${ }^{13,14}$

To specify our RANK model, we embed the model of household behavior (2) in general equilibrium, under the assumptions of constant $e=1$ and $\underline{a}=-\infty$. For simplicity, we write the model under perfect foresight, except for an unexpected shock at $t=0$, and we drop expectations whenever there is no ambiguity.

The behavior of the representative household can be summarized by the Euler equation

$$
U_{c}\left(c_{t}, n_{t}\right)=\beta\left(1+r_{t}^{e}\right) U_{c}\left(c_{t+1}, n_{t+1}\right)
$$

where $r_{t}^{e}$ denotes the ex ante real interest rate that agents expect to hold between periods $t$ and $t+$ 1 , and the labor supply equation, obtained by combining the intratemporal optimality conditions

\footnotetext{
${ }^{13}$ In contrast, complementarity generally decreases the multiplier in flexible-price models.

${ }^{14}$ Bilbiie (2009) and Eusepi and Preston (2015) also stress the importance of complementarities between consumption and labor for the aggregate effects of government spending.
} 
(3) and (4) and using $\tilde{w}_{t}=\left(1-\tau_{t}^{w}\right) w_{t}$ :

$$
\left(1-\tau_{t}^{w}\right) w_{t}=-\frac{U_{n}\left(c_{t}, n_{t}\right)}{U_{c}\left(c_{t}, n_{t}\right)}
$$

Aggregate consumption and labor are simply $C_{t}=c_{t}$ and $N_{t}=n_{t}$.

On the supply side, the model has a textbook New Keynesian structure. The final good is produced competitively as a CES aggregate of a continuum of intermediate goods with elasticity $\epsilon_{p}$. Each intermediate good is produced by a monopolist using labor, according to a production function $f\left(N_{t}\right)$. These monopolists set their prices subject to isoelastic demand from the final good producer and quadratic (Rotemberg 1982) price adjustment costs. Their objective is to maximize the present value of profits, discounted at the ex-ante real interest rate $r_{t}^{e}$. Since all monopolists face the same profit maximization problem, there exists an equilibrium in which they choose the same price and produce the same quantity. This symmetric equilibrium is characterized by an aggregate production function

$$
Y_{t}=f\left(N_{t}\right)
$$

and a New Keynesian Phillips curve ${ }^{15}$

$$
\log \left(1+\pi_{t}\right)=\kappa_{p}\left(\frac{w_{t}}{f^{\prime}\left(N_{t}\right)}-\frac{\epsilon_{p}-1}{\epsilon_{p}}\right)+\frac{1}{1+r_{t}^{e}} \frac{Y_{t+1}}{Y_{t}} \log \left(1+\pi_{t+1}\right) .
$$

The combination of a labor tax and the monopoly power of intermediate goods producers leads, in general, to a non-zero labor wedge, which we define as ${ }^{16}$

$$
\tau_{t} \equiv 1+\frac{U_{n}\left(C_{t}, N_{t}\right)}{U_{c}\left(C_{t}, N_{t}\right)} \frac{1}{f^{\prime}\left(N_{t}\right)}
$$

and which is strictly less than 1 under standard assumptions $U_{n}<0, U_{c}>0$, and $f^{\prime}>0$.

We assume that the monetary authority sets the real rate directly, as in Woodford (2011), and that the economy reverts to steady state once all shocks are past. ${ }^{17}$ The fiscal authority purchases an exogenous amount $G_{t}$ of the final good in every period, financed at the margin by some combination of changes in $T_{t}$ and $\tau_{t}^{w} \cdot{ }^{18}$ Market clearing requires that

$$
Y_{t}=C_{t}+G_{t}+\frac{\epsilon_{p}}{2 \kappa_{p}} \log \left(1+\pi_{t}\right)^{2} Y_{t}
$$

Given perfect foresight after date 0, the model delivers a mapping between a sequence of government spending $\left\{G_{t}\right\}_{t \geq 0}$ and a path of output $\left\{Y_{t}\right\}_{t \geq 0}$. The next proposition characterizes

\footnotetext{
${ }^{15}$ As is well known, to first order, this Phillips curve is equivalent to the more common specification with Calvo pricing and discounting with the household's stochastic discount factor $\beta U_{c, t+1} / U_{c, t}$.

${ }^{16}$ A welfare-maximizing planner choosing allocations would set $-U_{n, t} / U_{n, c}=f^{\prime}\left(N_{t}\right)$ —that is, a zero labor wedge (Chari, Kehoe and McGrattan 2007).

${ }^{17}$ This delivers determinacy in the representative-agent model with constant- $r$ monetary policy.

${ }^{18}$ With our assumption on monetary policy, whether $T_{t}$ or $\tau_{t}^{w}$ is used turns out not to matter (to first order) for the equilibrium allocation, nor does the timing of this revenue.
} 
the derivatives of this mapping - in other words, the model's fiscal multipliers.

Proposition 2. Assume that monetary policy sets a constant real rate $r$. The marginal effect of a time-s government spending shock on time-t output is given by

$$
\frac{d Y_{t}}{d G_{s}}=\frac{1}{1-(1-\tau) \mathrm{CI}} \cdot \mathbf{1}_{s=t}
$$

Proposition 2 shows that fiscal multipliers in this case are static (output only responds in the period in which the government spends) and depend only on the steady-state labor wedge $\tau$ and complementarity index CI. In the special case of separable preferences $(\mathrm{CI}=0)$, the multiplier is 1 , as in Woodford (2011). By contrast, in the special case of $\mathrm{GHH}$ preferences $(\mathrm{CI}=1)$, the multiplier is $1 / \tau$. More generally, since $\tau<1$, the multiplier is increasing in CI whenever it is positive.

Bilbiie (2011) previously derived an equivalent expression for the multiplier (14) under constant $r$ and general preferences, which he stated using a certain set of elasticities of marginal utility and production (see his proposition 3). Our contribution is to instead write the fiscal multiplier in terms of $\tau$ and CI, clarifying that it is governed by the interaction between these two steady-state parameters.

Intuitively, (14) can be understood as follows. Increasing output by $d Y=d G$ on the margin requires adding $d N=\left(1 / f^{\prime}(N)\right) d Y$ labor. By definition of $\mathrm{CI}$, this increase in labor, when real interest rates and therefore marginal utility $\lambda$ are held constant, increases consumption demand by $d C=C I \tilde{w} d N$. Since the after-tax wage $\tilde{w}$ equals $-U_{n} / U_{c}$ by (9), this increase in consumption demand is also equal to

$$
d C=-\mathrm{CI} \frac{U_{n}}{U_{c}} \frac{1}{f^{\prime}(N)} d Y=\mathrm{CI}(1-\tau) d Y,
$$

applying the definition of $\tau$. That is, satisfying demand $d G$ from the government increases demand from households by $\mathrm{CI}(1-\tau) d G$ in general equilibrium. This additional demand leads to a "second-round effect" of $\mathrm{CI}^{2}(1-\tau)^{2} d G$, and so on. The process converges to the multiplier $1+\mathrm{CI}(1-\tau)+\mathrm{CI}^{2}(1-\tau)^{2}+\cdots=(1-(1-\tau) \mathrm{CI})^{-1}$.

This argument is general, and only requires the definitions of $\mathrm{CI}$ and $\tau$ in terms of preferences and technology. In the model we have specified, however, the steady-state labor wedge $\tau$ takes the more specific form

$$
\tau=1-\left(1-\tau^{w}\right) \frac{\epsilon_{p}-1}{\epsilon_{p}} .
$$

Equation (15) shows the forces that shape the magnitude of the steady-state labor wedge in most New Keynesian models: the monopolistic distortion $\frac{\epsilon_{p}-1}{\epsilon_{p}}$, and distortive taxation $\tau^{w}$-which could be on either the employee side (as in this model), or on the firm side.

Recall that, in the case of GHH preferences, the fiscal multiplier is $1 / \tau$. In typical calibrations, this will be a large number, because $\epsilon_{p}$ is calibrated to be high and $\tau^{w}$ is calibrated to be low. For instance, Nakamura and Steinsson (2014) report a constant- $r$ multiplier of 7.00 under GHH preferences, reflecting their calibration choice of $\epsilon_{p}=7$ and $\tau^{w}=0$. Another typical calibration choice 
is to obtain an efficient steady state by offsetting monopolistic distortions with an employment subsidy of $\tau^{w}=-1 /\left(\epsilon_{p}-1\right)$. This yields $\tau=0$ and a locally infinite multiplier. Clearly, none of these calibration choices can be reconciled with Fact 3.

More generally, equations (14) and (15) show why there is a tension in matching Facts 1, 2, and 3 jointly. The back-of-the-envelope calculation from section 2 suggested that CI $\geq 0.92$ is necessary to match Facts 1 and 2. If we halve the Frisch elasticity or double the EIS, this bound becomes $\mathrm{CI} \geq 0.84$.

Meanwhile, equation (14) shows that to match Fact 3 with a multiplier below 2 in a RANK model, we need CI to be lower than $\frac{1-1 / 2}{1-\tau}=\frac{0.5}{1-\tau}$. Even with conservative choices for a labor income tax of $\tau^{w}=0.33$ (as in our model below) and $\epsilon=7$, equation (15) then requires $\mathrm{CI} \leq 0.88$. And this bound is only likely to tighten as we move to flexible-labor HANK models-whose high MPCs tend to create higher multipliers-suggesting that these models will be unable to solve the trilemma. Indeed, the next section verifies quantitatively that, with reasonable parametric assumptions, no such solution exists.

\section{The trilemma for HANK models}

HANK models are famed for delivering Fact 1 . One might hope that it is possible to parameterize these models to match Facts 2 and 3 as well. In this section, we demonstrate that this is not the case. In other words, we show that the trilemma has no solution in the space of New Keynesian models with a frictionless labor market.

To do this, we proceed as follows: we set up and calibrate a model that always features an average quarterly MPC of 0.25 , thereby matching Fact 1 by construction. By varying the degree of complementarity in preferences, we then assess the quantitative tradeoff between matching Fact 2 and Fact 3 . We show that it is impossible to match both.

\subsection{HANK with GHH-plus preferences}

Here we set up and parameterize our HANK model with flexible labor supply and an arbitrary degree of consumption-labor complementarity in preferences.

Households. Households solve the dynamic problem introduced in equation (2). Since we are solving the model numerically, we must now specify a functional form. We consider a flexible felicity function with the following form:

$$
U(c, n)=\frac{1}{1-\sigma}\left(c-\varphi \alpha \frac{n^{1+v}}{1+v}\right)^{1-\sigma}-\varphi(1-\alpha) \frac{n^{1+v}}{1+v}
$$

We call these "GHH-plus preferences", since they nest isoelastic separable preferences (when $\alpha=$ 0 ) and GHH preferences (when $\alpha=1$ ). This choice is certainly not the only possible functional 
form for $U(c, n)$ with this property (see, for instance, Bilbiie 2020). But it has two additional properties that make it ideal for our purposes. First, it is convenient for computation: as we show in appendix $\mathrm{E}, U_{c}$ can be inverted to provide analytical expressions for $c$ and $n$, which means that Carroll (2006)'s method of endogenous gridpoints can be applied. Second, as we show in appendix A.4, it delivers a simple expression for CI:

$$
\mathrm{CI}(e, a)=\frac{\alpha U_{c}(e, a)}{\alpha U_{c}(e, a)+1-\alpha} \in[0,1] .
$$

Equation (17) shows that $\mathrm{CI}$ is effectively parameterized by $\alpha$, with $\mathrm{CI}=0$ for separable preferences and $\mathrm{CI}=1$ for $\mathrm{GHH}$, as expected. In intermediate cases, $\mathrm{CI}$ is increasing in $\alpha$ but varies across households according to their marginal utilities of consumption.

Asset markets. This economy has two assets in positive net supply: public debt in the form of one-period real bonds, and equity in intermediate goods firms. Since we assume certainty equivalence at the aggregate level, financial market equilibrium requires that these two assets offer the same return ex ante. Let $p_{t}$ be the ex-dividend price of equity, and $d_{t}$ be dividends. Then we have

$$
1+r_{t}^{e}=\mathbb{E}_{t}\left[\frac{d_{t+1}+p_{t+1}}{p_{t}}\right]
$$

where, as in section $3, r_{t}^{e}$ denotes the real interest rate that agents expect to prevail between time $t$ and time $t+1$. Along perfect-foresight paths, the ex-post real interest rate $r_{t}$ that enters agents' budget constraints in (2) is always equal to $r_{t-1}^{e}$. However, an unexpected aggregate shock at $t=0$ may result in capital gains and imply $r_{0} \neq r_{-1}^{e}$. Assuming that all households hold the same portfolio of bonds and equity, each of them experiences the same ex-post interest rate, equal to a weighted average of the realized return on equity and bonds:

$$
1+r_{t}=\underbrace{\frac{p_{t-1}}{p_{t-1}+B_{t-1}}}_{\text {equity share }} \frac{d_{t}+p_{t}}{p_{t-1}}+\underbrace{\frac{B_{t-1}}{p_{t-1}+B_{t-1}}}_{\text {bond share }}\left(1+r_{t-1}^{e}\right)
$$

where the last term in equation (19) reflects the fact that the return on government bonds at time $t$ is always equal to $r_{t-1}^{e}$, since these are one-period real bonds.

Supply side. The supply side is the same as in section 3: the final good is produced competitively as a CES aggregate of intermediate goods with elasticity $\epsilon_{p}$, and intermediate goods firms are monopolistically competitive with Rotemberg pricing.

We parameterize the production function for intermediate goods as:

$$
f\left(N_{t}\right)=Z N_{t}-F
$$

The fixed cost $F$ allows us to target firms' steady-state net profits, and therefore the value of their 
equity, independently of the elasticity $\epsilon_{p}$. This is useful because the two play different roles in the model. The elasticity affects the value of the labor wedge and therefore the fiscal multiplier. Firm equity is important because it is an asset held by households and therefore determines the overall degree of liquidity in the economy, which in turn is a key determinant of MPCs.

Aggregate firm dividends are then

$$
d_{t}=Y_{t}-w_{t} N_{t}-\frac{\epsilon_{p}}{2 \kappa} \log \left(1+\pi_{t}\right)^{2} Y_{t}
$$

where the last term is the price adjustment cost. By equation (18), the value of firms $p_{t}$ is the present discounted value of their future dividends.

Government policy. The government purchases an exogenous amount of final goods $G_{t}$, runs the tax-and-transfer system, and issues one-period real debt $B_{t}$. It provides a constant transfer $T$. Its overall budget constraint in period $t$ is given by

$$
B_{t}+\tau_{t}^{w} w_{t} N_{t}=\left(1+r_{t-1}^{e}\right) B_{t-1}+G_{t}+T
$$

Following Auclert et al. (2018), we assume that the government follows a fiscal rule such that increases in spending relative to steady state are initially financed using increases in debt, which are then paid back at a rate of $1-\rho_{B}$ each period,

$$
B_{t}-B_{s s}=\rho_{B}\left(B_{t-1}-B_{s s}+G_{t}-G_{s s}\right)
$$

where we call $\rho_{B} \in[0,1)$ the "persistence" of debt, and a balanced-budget rule corresponds to $\rho_{B}=0$. Given (23), the government adjusts $\tau_{t}^{w}$ so that (22) is satisfied at all times.

Just as in section 3 , we specify the monetary policy rule to be $r_{t}^{e} \equiv r_{s s}$. We show explicitly in section 4.5 that this represents a moderate degree of accommodation, in between the zero lower bound and an active Taylor rule.

Finally, goods market clearing requires that

$$
Y_{t}=C_{t}+G_{t}+\frac{\epsilon_{p}}{2 \kappa_{p}} \log \left(1+\pi_{t}\right)^{2} Y_{t}
$$

By Walras's law, this is equivalent to asset market clearing $B_{t}+p_{t}=A_{t}$.

\subsection{Calibration}

As discussed at the top of this section, our goal is to assess the tradeoff between matching Fact 2 and Fact 3, conditional on matching Fact 1. Our calibration therefore varies $\alpha$ holding other key moments constant, including a quarterly average MPC of 0.25. It is well known that HANK models with a plausible supply of total assets cannot generate such large MPCs without additional features, such as illiquid assets or discount factor heterogeneity. We follow the latter route and 
use a simple form of permanent discount factor heterogeneity: we assume that one half of the population has discount factor $\beta_{1}$ and one half of the population has discount factor $\beta_{2}<\beta_{1}$, and use $\left(\beta_{1}, \beta_{2}\right)$ to jointly achieve our targets for the average MPC and the real interest rate $r$.

The model period is one quarter. For the most part, our calibration follows McKay et al. (2016), a prominent example of a HANK model with a canonical supply side, sticky prices, and flexible wages. We set the real interest rate $r$ to an annualized value of $2 \%$ and the Frisch elasticity $1 / v$ to 0.5 . The elasticity of intertemporal substitution (EIS) varies across individuals, and we calibrate $\sigma$ to target an average EIS of 0.5 . $^{19}$ We choose the disutility of labor $\varphi$ to normalize effective aggregate labor to 1 , and aggregate labor productivity $Z$ to normalize aggregate output to 1 .

We assume that idiosyncratic labor productivity $e$ follows an $\mathrm{AR}(1)$ process with a persistence of 0.966 as in McKay et al. (2016) and calibrate the variance of innovations to match the standard deviation of log gross earnings of 0.92 documented by Song, Price, Guvenen, Bloom and von Wachter (2019). We discretize the labor productivity process as a 25-point Markov chain. We set the steady-state value of bonds to annual GDP (0.55), the steady-state labor tax $\tau^{w}=0.334$, and the steady-state transfer $T=0.143 \cdot w N$ all to match Auclert and Rognlie (2020), who show that this specification fits the relationship between pre-tax and post-tax-and-transfer income with an $R^{2}$ of $99 \%$. Together with a standard value for the elasticity of substitution, $\epsilon_{p}=7$, these choices imply a steady-state labor wedge of $\tau=0.43$, as in our back-of-the-envelope calculations from section 3 .

Following McKay et al. (2016), we set the ratio of liquid assets to annual GDP to 1.4. In our model, this includes the value of firm equity as well as government bonds, and we calibrate the fixed cost $F$ so that firm equity equals assets minus bonds, which is 0.85 times annual GDP. Together with the fiscal rule, these assumptions imply $G=0.177$. We assume that households cannot borrow, $\underline{a}=0$. Finally, we set the slope of the Phillips curve to $\kappa_{p}=0.01$. This low value is irrelevant for our fiscal multiplier results under constant $r$, since it only affects the dynamics of inflation. We set it to avoid the explosively large multipliers with more flexible prices when nominal rates are constant (the so-called "paradox of flexibility"), which would only exacerbate the trilemma.

Table 1 summarizes our calibration. The upper panel contains the parameters we hold fixed, and the lower panel shows the parameters that we calibrate internally. Appendix E discusses our solution procedure.

\subsection{The MPE-multiplier dilemma}

Figure 2 presents our main quantitative result. The figure summarizes the model's performance in matching average annual MPEs (Fact 2) and fiscal multipliers (Fact 3) for the full range of possible values of the complementarity index. Each blue circle corresponds to the outcomes of a model with a different value of $\alpha \in\{0,0.1, \ldots, 0.9,1\}$. Recall that each of these models is calibrated to a quarterly MPC of 0.25 , so by construction each of these circles matches Fact 1.

\footnotetext{
${ }^{19}$ Appendix A.4 shows how to calculate the EIS for GHH-plus preferences.
} 
Table 1: Fixed and calibrated parameters

\begin{tabular}{llc}
\hline parameter & name & value/target \\
\hline $1 / v$ & Frisch elasticity & 0.5 \\
$\rho_{e}$ & persistence of income process & 0.966 \\
$\tau^{w}$ & wage tax rate & 0.334 \\
$T$ & transfer & $0.143 \cdot w \mathrm{~N}$ \\
$\epsilon_{p}$ & elasticity of substitution & 7 \\
$\kappa_{p}$ & NKPC slope & 0.01 \\
$B$ & government bonds & $0.55 \cdot 4 Y$ \\
$\rho_{B}$ & persistence of public debt & 0.9 \\
$\underline{a}$ & borrowing constraint & 0 \\
\hline$\beta_{1}$ & upper discount factor & $r=0.02 / 4$ \\
$\beta_{2}$ & lower discount factor & $\mathrm{MPC}=0.25$ \\
$1 / \sigma$ & U & average EIS $=0.5$ \\
$\varphi$ & disutility of labor & $N=1$ \\
$Z$ & aggregate labor productivity & $Y=1$ \\
$\sigma_{e}$ & std of income shocks & $\operatorname{Var}\left[\log \left(n_{i} e_{i}\right)\right]=0.92^{2}$ \\
$F$ & fixed cost & $p=0.85 \cdot 4 Y$ \\
\hline
\end{tabular}

The upper panel lists directly calibrated parameters. The lower panel lists parameters calibrated to match some target, whose values will depend on the choice of $\alpha$.

Separable preferences: $\left(\beta_{1}, \beta_{2}\right)=(0.978,0.923)$. GHH: $\left(\beta_{1}, \beta_{2}\right)=(0.987,0.970)$.

The $x$-axis plots the average annual MPE for comparison with Fact 2 . This is computed as the (negative of) the sum of the responses of earned income in the first four quarters to a one-time unit lump-sum transfer to all agents in quarter 0 . The $y$-axis plots two measures of the fiscal multiplier for comparison with Fact 3. This is in response to an infinitesimal AR(1) shock to government spending with a quarterly persistence of 0.9, similar to Auclert et al. (2018). On the left panel, we plot the impact multiplier $d Y_{0} / d G_{0}$. On the right panel, we plot cumulative multipliers, defined as $\frac{\sum_{t}(1+r)^{-t} d Y_{t}}{\sum_{t}(1+r)^{-t} d G_{t}}$. The green rectangle shows the range of values that are acceptable according to both facts.

None of the models gets close quantitatively, at least if we judge using cumulative multipliers on the right panel: models that have plausible values for the MPE have far too large fiscal multipliers, and vice versa. It takes high complementarity to match Fact 2, but low complementarity to match Fact 3. This is the trilemma for New Keynesian models. We now provide more detailed context for this conclusion, and discuss how it relates to proposition 1 and proposition 2.

The MPEs in figure 2 reflect the aggregate implications of proposition 1. Recall that the Frisch elasticity and the average EIS are calibrated to be the same number. While agents have different ratios of earned income to consumption, the average ratio is $\left(1-\tau^{w}\right) w N / C=0.66 / 0.82=0.80$. We therefore expect the quarterly MPE to be roughly $0.80 \times(1-\mathrm{CI}) \times 0.25=(1-\mathrm{CI}) \times 0.20$. Indeed, the quarterly MPE for the separable model is close to this value, though slightly lower at 

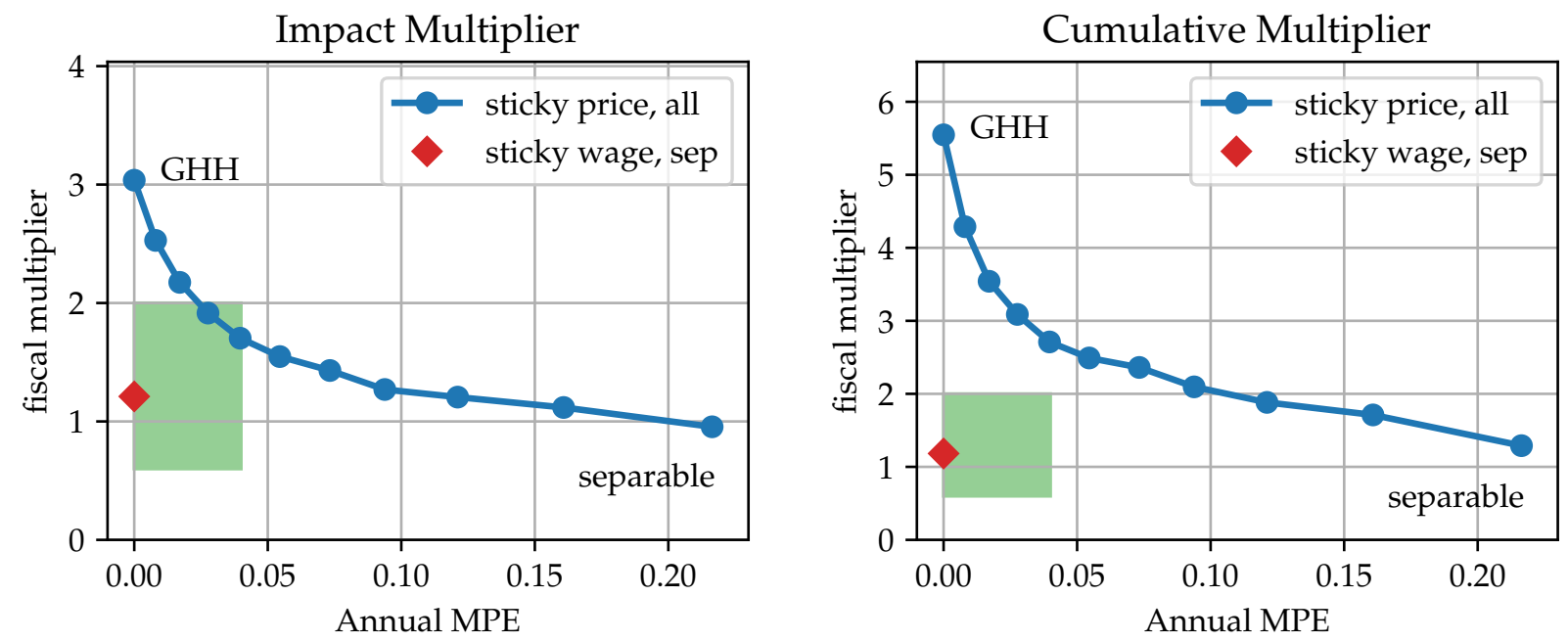

Figure 2: The tradeoff between fiscal multipliers and MPEs

0.16, and the annual MPE is 0.23 , far outside the acceptable range from Fact $2 .{ }^{20}$ Only calibrations near GHH fall inside the acceptable range: it takes high complementarity to match Fact 2.

As in the representative-agent case of proposition 2, the multiplier is rising in CI, but now high MPCs provide further amplification. Consistent with Auclert et al. (2018), this amplification is especially strong for the cumulative multiplier, thanks to intertemporal spillovers in consumption. For instance, under GHH preferences, proposition 2 implies a constant- $r$ multiplier of $1 / \tau=2.32$, both on impact and cumulatively, but here the cumulative multiplier is above 5 . Only calibrations near separable fall inside the acceptable range: it takes low complementarity to match Fact $3 .{ }^{21}$

The best overall fit is achieved by the calibrations with intermediate levels of complementarity: $\alpha=0.6$ and $\alpha=0.7$. These feature annual MPEs of 0.040 and 0.028 , and impact fiscal multipliers of 1.70 and 1.91, both just within the acceptable range. But the cumulative multipliers of 2.71 and 3.09 are still well outside the acceptable range, and these calibrations therefore do not solve the trilemma.

\subsection{Parameters other than complementarity}

In the previous section, we showed that by varying complementarity from $\alpha=\mathrm{CI}=1$ to $\alpha=$ $\mathrm{CI}=0$ while targeting a realistic MPC, we could match MPEs or multipliers, but not both. This is the central tradeoff in our trilemma.

Could varying parameters other than $\alpha$ relax the trilemma? In appendix B, we consider several

\footnotetext{
${ }^{20}$ The actual quarterly MPE of 0.16 is lower than the 0.20 calculated above because proposition 1 holds at the individual rather than aggregate level. Households with high MPCs tend to have low earnings and therefore low MPEs. Ignoring this negative correlation, and applying proposition 1 directly to aggregates, overstates the MPE.

${ }^{21}$ For the separable sticky-price case, the impact (though not the cumulative) multiplier is slightly lower in HANK than RANK, due to peculiar distributional forces discussed in appendix C. In general, we have found that these forces make the separable calibration somewhat fragile.
} 
possibilities, showing how figure 2 changes in each case. First, motivated by (6), which shows that MPEs at the individual level are proportional to Frisch/EIS, we consider either a higher elasticity of intertemporal substitution (1.0 instead of 0.5 ) or a lower Frisch elasticity (0.25 instead of 0.5). Both options, especially the lower Frisch elasticity, achieve lower MPEs and lower impact multipliers, moving some intermediate- $\alpha$ calibrations deeper into the acceptable range. Cumulative multipliers for these calibrations are closer to the acceptable range, but still outside it.

Second, motivated by (14), which shows that multipliers are decreasing in the labor wedge $\tau$ in the presence of complementarity, we consider a much higher steady-state markup: 50\% rather than $16.7 \%$, leading to a labor wedge of $\tau=.56$ rather than $\tau=.43$. We implement this by lowering the elasticity of substitution $\epsilon_{p}$ from 7 to 3 , while adjusting fixed costs and renormalizing to keep the total value of firm shares constant and the steady-state allocation identical. This leads to mild decreases in both the impact and cumulative multiplier, but makes little qualitative difference: intermediate- $\alpha$ calibrations deliver acceptable results for the impact multiplier, but not for the cumulative multiplier.

Finally, we revisit our benchmark fiscal rule, which pays for spending by raising the flat tax on wages. If the marginal revenue to pay for government spending is instead raised using a progressive tax, then we might expect higher multipliers, since richer taxpayers have lower MPCs and their consumption will fall less in response to taxation. ${ }^{22}$ To consider this, we modify our framework so that to pay for spending, $\tau^{w}$ is raised only on the 10 highest income states $e$ (out of 25). This has limited effect on impact multipliers, but drastically increases the cumulative multiplierwhich is now nearly 7 in the GHH case, and well above 3 for intermediate- $\alpha$ cases-thereby worsening the trilemma.

Overall, although modifying some parameters brings us closer to a solution, none of these changes on its own can resolve the trilemma for cumulative multipliers, and one (progressive taxation) makes the puzzle worse. A highly specific combination of these assumptions-high EIS, low Frisch, high markups, a flat tax, and intermediate complementarity-might bring both MPEs and multipliers into the acceptable range. In section 5, however, we will pursue a more general and robust solution.

\subsection{Alternative monetary and fiscal policies}

In this section, we return to the original calibration and consider alternative monetary and fiscal policies. Since none of these policies will change the calibrated steady state, MPCs and MPEs are unaffected, and we focus on fiscal multipliers.

First, we consider monetary policy. Our Fact 3 is that multipliers even under accommodative monetary policy - where the central bank does not raise rates in response to a fiscal expansionare no greater than 2 . In our baseline exercises, we considered a fixed real interest rate as a moderate version of accommodative policy. Empirically, however, interest rates are often pegged nom-

\footnotetext{
${ }^{22}$ Indeed, the previous version of the paper was an example of this: lump-sum transfers were indexed to aggregate labor income, which made the tax system more progressive in a boom and led to higher multipliers than here.
} 
Table 2: Cumulative Fiscal Multipliers with Alternative Monetary and Fiscal Policies

\begin{tabular}{lccccccc}
\hline & \multicolumn{3}{c}{ Monetary } & & \multicolumn{3}{c}{ Fiscal } \\
\cline { 2 - 3 } Separable & Taylor rule & constant $r$ & 3-year peg & & $\rho_{B}=0$ & $\rho_{B}=0.9$ & $\rho_{B}=0.95$ \\
$\alpha=0.5$ & 0.77 & 1.29 & 118.26 & & 1.29 & 1.29 & 1.29 \\
GHH & 1.14 & 2.49 & 3.48 & & 2.49 & 2.49 & 2.49 \\
\hline Sticky Wage & 2.40 & 5.55 & 6.06 & & 5.55 & 5.55 & 5.55 \\
\hline
\end{tabular}

inally in the short term, due to an effective lower bound. We now consider this case as well, implemented assuming constant nominal interest rates for 3 years, followed by reversion to an active Taylor rule $i_{t}=r+\phi \pi_{t}$ with a coefficient on inflation of $\phi=1.25$. For completeness, we also report results for the non-accommodative case where this active Taylor rule is in place throughout.

The left panel of table 2 displays cumulative fiscal multipliers in each of these cases for different levels of complementarity $\alpha \in\{0,1 / 2,1\}$. Relative to constant $r$, an active Taylor rule pushes down the multiplier, bringing it closer to its flexible-price level. With constant nominal interest rates, on the other hand, inflation pushes down real interest rates and the multiplier increases even further, consistent with Christiano, Eichenbaum and Rebelo (2011). The effect is particularly extreme for separable preferences, where inflation is more responsive and the multiplier in table 2 is near an asymptote. This form of accommodative policy therefore makes the trilemma even worse.

The right panel of table 2 displays cumulative fiscal multipliers under three fiscal policy rules: balanced budget with $\rho_{B}=0$, our baseline with $\rho_{B}=0.9$, and very persistent debt $\rho_{B}=0.95$. The table shows an intriguing property of the sticky price model: in contrast to typical HANK models (Auclert et al. 2018), the timing of fiscal deficits is irrelevant for the multiplier. As we establish formally in appendix F.1, this reflects an unusual form of "Ricardian equivalence", which is due to the interaction of our tax system with tradable firm equity: both the path of after-tax wages $\left(1-\tau_{t}^{w}\right) w_{t}$ and the total value of assets are unaffected to first order by the path of $\tau_{t}^{w}$ that the government uses to finance its spending. Given that there is some empirical evidence that deficit financing tends to raise the fiscal multiplier, this provides another argument against the sticky-price, flexible-wage model. It also implies that conditional on spending, no path for bond financing can ever lower the multiplier and solve the trilemma.

\section{Solving the trilemma with sticky wages}

To solve the trilemma, we propose to push workers off their labor supply curves in the short run, imposing nominal wage stickiness and demand-determined labor in the spirit of Erceg, Henderson and Levin (2000). This does not avoid the problem of high multipliers when CI is high: indeed, as appendix A.3 makes clear, the multiplier result in proposition 2 is identical under sticky 
wages. ${ }^{23}$ It does, however, imply that MPE $=0$, which allows us to choose low CI and obtain multipliers consistent with Fact 3 without contradicting Fact 2. For simplicity, in our calibration we will choose separable preferences, $\mathrm{CI}=0$.

\subsection{Model setup}

We introduce sticky wages by borrowing the microfoundation of the wage Phillips curve from Auclert et al. (2018), and adapting it to the affine tax system in (2). ${ }^{24}$ Households solve a version of the problem in (2), but they now take their hours $n$ as given. This makes their MPE equal to 0 by construction, and the model is therefore immediately consistent with Fact 2.

Aggregate hours are determined by a labor union, who sets wages on behalf of households subject to satisfying the aggregate demand for labor from final goods firms. In appendix F.2, we show that the maximization problem of these unions yields a wage Phillips curve of

$$
\log \left(1+\pi_{t}^{w}\right)=\kappa_{w}\left[N_{t} U_{t}^{n}-w_{t} N_{t}\left(1-\tau_{t}^{w}\right)\left(\frac{\epsilon_{w}-1}{\epsilon_{w}}\right) U_{t}^{c}\right]+\beta \log \left(1+\pi_{t+1}^{w}\right)
$$

where $\pi_{t}^{w}$ denotes nominal wage inflation, $U_{t}^{n}$ is the average marginal disutility of labor and $U_{t}^{c}$ is the productivity-weighted average marginal utility of consumption. In the representative-agent counterpart of the model, these are simply the partials $U_{N}$ and $U_{C}$ of the representative agent, and therefore (25) coincides with the formulation in Erceg et al. (2000).

We assume that prices are flexible $\left(\kappa_{p}=\infty\right)$, so that intermediate goods producers always charge their desired markup. Hence, the real wage is constant at $w_{t}=Z\left(\frac{\epsilon_{p}-1}{\epsilon_{p}}\right)$, and price and wage inflation coincide, $\pi_{t}^{w}=\pi_{t}$. Finally, since wage adjustment incurs a cost in terms of utils and not goods, goods market clearing becomes simply $Y_{t}=C_{t}+G_{t}$. This completes the formulation of the sticky-wage model.

\subsection{Results}

We calibrate the model as in section 4.2. We assume separable preferences $(\alpha=0)$, and calibrate the model to deliver Fact 1. Figure 2 shows that the model can then deliver Facts 2 and 3 simultaneously. The MPE is 0 by construction. The impact fiscal multiplier is 1.21 and the cumulative fiscal multiplier is 1.18, well within the range of Fact 3 . The red line of figure 3 shows that the impulse responses of private consumption feature a moderate degree of crowding in for about 20 quarters.

Table 2 shows that the sticky wage model is also well-behaved with respect to alternative assumptions about monetary and fiscal policy. Alternative monetary rules affect the multiplier

\footnotetext{
${ }^{23}$ The only difference is that we must use $\mathrm{CI}=\frac{U_{n c} / U_{n}}{U_{c c} / U_{c}}$ from lemma 1 to define CI directly in terms of utility, since definition (5) no longer makes sense when workers are not on their labor supply curves. This CI can be interpreted as the MPC out of earnings from demand-determined labor, divided by the wage markdown.

${ }^{24}$ The tax code affects marginal incentives to work, and therefore the wage-setting problem of labor unions.
} 

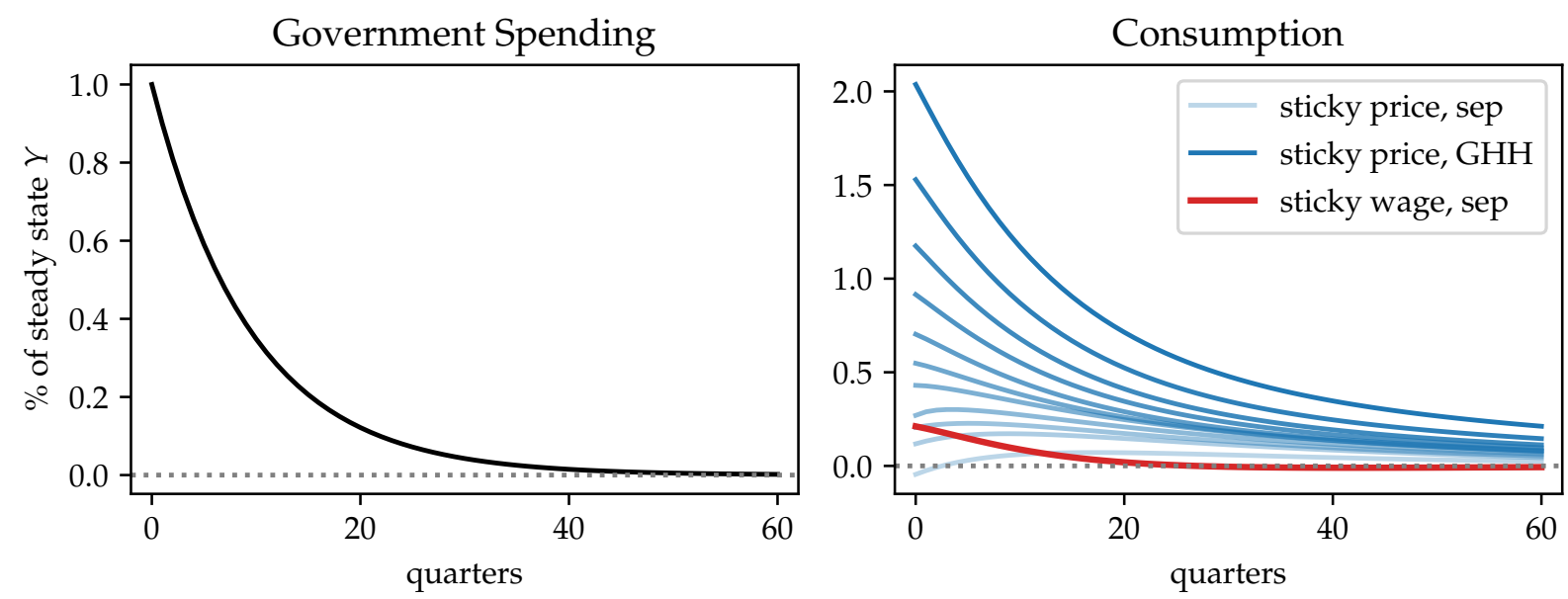

Figure 3: Government Spending and the Response of Private Consumption

Each blue line corresponds to a different value of CI, going from $\alpha=0$ (light) to $\alpha=1$ (dark) in steps of 0.1 .

moderately. Alternative fiscal policy rules affect the multiplier to a greater extent, with more backloaded fiscal policy generating larger fiscal multipliers. Under all of these assumptions, however, multipliers remain within the range allowed by Fact 3. Hence, the sticky wage model provides a solution to the trilemma.

There are other reasons to prefer the sticky-wage, flexible-price model to its sticky-price, flexiblewage counterpart. First, as appendix figure 8 shows, the equity price is mildly procyclical instead of strongly countercyclical. ${ }^{25}$ This gives the model a chance of fitting both the cyclicality of the price-cost margin (e.g. Nekarda and Ramey 2020) and the response of equity prices to government spending shocks. It also avoids the large redistribution effects associated with firm ownership, which Broer et al. (2020) show to be problematic, and which drive peculiar heterogeneity in impulse responses in our own flexible-wage model, as appendix $\mathrm{C}$ discusses in detail.

\section{Conclusion}

New Keynesian models with frictionless labor supply face a trilemma: they cannot simultaneously match high MPCs, low MPEs, and fiscal multipliers that are moderate under accommodative monetary policy. Our proposed solution is to take workers off their short-run labor supply curves. This directly implies low MPEs, allowing us to use separable preferences, which can then match high MPCs and moderate fiscal multipliers. We achieve this with sticky wages and demand-determined labor in a HANK model. This is a simple adaptation of the New Keynesian sticky-wage tradition. An alternative route would be to introduce more explicit microfoundations

\footnotetext{
${ }^{25}$ To obtain a simple benchmark HANK model, one may dispense with intermediate goods-producing sector and thus economy-wide profits altogether. This simplifies the asset structure of the economy without affecting the dynamics of the model much.
} 
for frictional labor supply: for instance, search frictions, as in Gornemann et al. (2016) and Ravn and Sterk (2017).

While we argue that there is no robust way to solve the trilemma without adding labor market frictions, some calibrations come closer than others. Preferences with an intermediate degree of labor-consumption complementarity, between separable and $\mathrm{GHH}$, achieve the best tradeoff of MPEs and multipliers. A higher elasticity of intertemporal substitution, or lower Frisch elasticity, brings down MPEs relative to MPCs, and financing spending with more regressive taxes leads to lower multipliers. For preferences with complementarity, a high labor wedge can also bring the multiplier down to a more reasonable level. Finally, if monetary policy is active (with a high Taylor rule coefficient), rather than accommodative as in Fact 3, the model's predictions are closer to neoclassical. This sidesteps the trilemma, but only as long as active policy is in force. 


\section{References}

Aguiar, Mark and Erik Hurst, "Deconstructing Life Cycle Expenditure," Journal of Political Economy, June 2013, 121 (3), 437-492.

Aiyagari, S. Rao and Ellen R. McGrattan, "The Optimum Quantity of Debt," Journal of Monetary Economics, October 1998, 42 (3), 447-469.

Alves, Felipe, Greg Kaplan, Benjamin Moll, and Giovanni L Violante, "A further look at the propagation of monetary policy shocks in HANK," Journal of Money, Credit and Banking, 2020, 52 (S2), 521-559.

Auclert, Adrien, "Monetary Policy and the Redistribution Channel," American Economic Review, June 2019, 109 (6), 2333-2367.

_ and Matthew Rognlie, "Inequality and Aggregate Demand," Working Paper, January 2020.

_ , Bence Bardóczy, Matthew Rognlie, and Ludwig Straub, "Using the Sequence-Space Jacobian to Solve and Estimate Heterogeneous-Agent Models," Working Paper 26123, National Bureau of Economic Research, November 2020.

_ , Matthew Rognlie, and Ludwig Straub, “The Intertemporal Keynesian Cross," Working Paper 25020, National Bureau of Economic Research, September 2018.

Bayer, Christian, Ralph Luetticke, Lien Pham-Dao, and Volker Tjaden, "Precautionary Savings, Illiquid Assets, and the Aggregate Consequences of Shocks to Household Income Risk," Econometrica, 2019, 87 (1), 255-290.

Berger, David, Veronica Guerrieri, Guido Lorenzoni, and Joseph Vavra, "House Prices and Consumer Spending," Review of Economic Studies, July 2018, 85 (3), 1502-1542.

Bilbiie, Florin O., "Nonseparable Preferences, Fiscal Policy Puzzles, and Inferior Goods," Journal of Money, Credit and Banking, 2009, 41 (2-3), 443-450.

_ , "Nonseparable Preferences, Frisch Labor Supply, and the Consumption Multiplier of Government Spending: One Solution to a Fiscal Policy Puzzle," Journal of Money, Credit and Banking, February 2011, 43 (1), 221-251.

_ , "A GHH-CRRA Utility for Macro: Complementarity, Income, and Substitution," Manuscript, April 2020.

- and Roland Straub, "Fiscal Policy, Business Cycles and Labor-Market Fluctuations," Manuscript, 2004.

Broer, Tobias, Niels-Jakob Harbo Hansen, Per Krusell, and Erik Öberg, "The New Keynesian Transmission Mechanism: A Heterogeneous-Agent Perspective," Review of Economic Studies, January 2020, 87 (1), 77-101. 
Carroll, Christopher D., "The Method of Endogenous Gridpoints for Solving Dynamic Stochastic Optimization Problems," Economics Letters, 2006, 91 (3), 312-320.

Cesarini, David, Erik Lindqvist, Matthew J. Notowidigdo, and Robert Östling, "The Effect of Wealth on Individual and Household Labor Supply: Evidence from Swedish Lotteries," American Economic Review, December 2017, 107 (12), 3917-3946.

Chari, V. V., Patrick J. Kehoe, and Ellen R. McGrattan, "Business Cycle Accounting," Econometrica, May 2007, 75 (3), 781-836.

Christiano, Lawrence, Martin Eichenbaum, and Sergio Rebelo, "When Is the Government Spending Multiplier Large?," Journal of Political Economy, February 2011, 119 (1), 78-121.

Erceg, Christopher J., Dale W. Henderson, and Andrew T. Levin, “Optimal Monetary Policy with Staggered Wage and Price Contracts," Journal of Monetary Economics, October 2000, 46 (2), 281-313.

Eusepi, Stefano and Bruce Preston, "Consumption Heterogeneity, Employment Dynamics and Macroeconomic Co-Movement," Journal of Monetary Economics, April 2015, 71, 13-32.

Fagereng, Andreas, Martin B. Holm, and Gisle J. Natvik, "MPC Heterogeneity and Household Balance Sheets," Manuscript, March 2020.

Galí, Jordi, J. David López-Salido, and Javier Vallés, “Understanding the Effects of Government Spending on Consumption," Journal of the European Economic Association, 2007, 5 (1), 227-270.

Gornemann, Nils, Keith Kuester, and Makoto Nakajima, "Doves for the Rich, Hawks for the Poor? Distributional Consequences of Monetary Policy," Manuscript, April 2016.

Greenwood, Jeremy, Zvi Hercowitz, and Gregory W. Huffman, "Investment, Capacity Utilization, and the Real Business Cycle," American Economic Review, June 1988, 78 (3), 402-417.

Hagedorn, Marcus, Iourii Manovskii, and Kurt Mitman, “The Fiscal Multiplier," Working Paper 25571, National Bureau of Economic Research, February 2019.

Imbens, Guido W., Donald B. Rubin, and Bruce I. Sacerdote, "Estimating the Effect of Unearned Income on Labor Earnings, Savings, and Consumption: Evidence from a Survey of Lottery Players," American Economic Review, September 2001, 91 (4), 778-794.

Jappelli, Tullio and Luigi Pistaferri, "Fiscal Policy and MPC Heterogeneity," American Economic Journal: Macroeconomics, October 2014, 6 (4), 107-136.

Kaplan, Greg and Giovanni L. Violante, "A Model of the Consumption Response to Fiscal Stimulus Payments," Econometrica, July 2014, 82 (4), 1199-1239.

_ , Benjamin Moll, and Giovanni L. Violante, "Monetary Policy According to HANK," American Economic Review, March 2018, 108 (3), 697-743. 
McKay, Alisdair, Emi Nakamura, and Jón Steinsson, "The Power of Forward Guidance Revisited," American Economic Review, October 2016, 106 (10), 3133-3158.

Monacelli, Tommaso and Roberto Perotti, "Fiscal Policy, Wealth Effects, and Markups," Working Paper 14584, National Bureau of Economic Research, December 2008.

Mountford, Andrew and Harald Uhlig, "What Are the Effects of Fiscal Policy Shocks?," Journal of Applied Econometrics, 2009, 24 (6), 960-992.

Nakamura, Emi and Jón Steinsson, "Fiscal Stimulus in a Monetary Union: Evidence from US Regions," American Economic Review, March 2014, 104 (3), 753-792.

Nekarda, Christopher J and Valerie A Ramey, "The cyclical behavior of the price-cost markup," Journal of Money, Credit and Banking, 2020, 52 (S2), 319-353.

Parker, Jonathan A. and Nicholas S. Souleles, "Reported Effects versus Revealed-Preference Estimates: Evidence from the Propensity to Spend Tax Rebates," American Economic Review: Insights, December 2019, 1 (3), 273-290.

Pencavel, John, "Chapter 1 - Labor Supply of Men: A Survey," in "Handbook of Labor Economics," Vol. 1, Elsevier, January 1986, pp. 3-102.

Ramey, Valerie A., "Can Government Purchases Stimulate the Economy?," Journal of Economic Literature, 2011, 49 (3), 673-685.

_ , "Ten Years after the Financial Crisis: What Have We Learned from the Renaissance in Fiscal Research?," Journal of Economic Perspectives, May 2019, 33 (2), 89-114.

Ravn, Morten O. and Vincent Sterk, "Job Uncertainty and Deep Recessions," Journal of Monetary Economics, October 2017, 90 (Supplement C), 125-141.

Rotemberg, Julio J., "Sticky Prices in the United States," Journal of Political Economy, December 1982,90 (6), 1187-1211.

Song, Jae, David J. Price, Fatih Guvenen, Nicholas Bloom, and Till von Wachter, "Firming Up Inequality," Quarterly Journal of Economics, February 2019, 134 (1), 1-50.

Woodford, Michael, "Simple Analytics of the Government Expenditure Multiplier," American Economic Journal: Macroeconomics, 2011, 3 (1), 1-35. 


\section{A Proofs}

\section{A.1 Proof of Lemma 1}

Proof. Applying the implicit function theorem to (3) yields

$$
U_{c c} \frac{\partial c(\lambda, \tilde{w})}{\partial \tilde{w}}+U_{c n} \frac{\partial n(\lambda, \tilde{w})}{\partial \tilde{w}}=0
$$

Rearrange to get

$$
\frac{\partial c(\lambda, \tilde{w})}{\partial \tilde{w}} / \frac{\partial n(\lambda, \tilde{w})}{\partial \tilde{w}}=-\frac{U_{c n}}{U_{c c}}
$$

and then divide by the ratio of (4) and (3), $\tilde{w}=-U_{n} / U_{c}$, to obtain the desired result

$$
\mathrm{CI}=\frac{\partial c(\lambda, \tilde{w})}{\partial \tilde{w}} / \tilde{w} \frac{\partial n(\lambda, \tilde{w})}{\partial \tilde{w}}=\frac{U_{n c} / U_{n}}{U_{c c} / U_{c}} .
$$

For separable preferences, $U_{n c}=0$, and it is clear that $\mathrm{CI}=0$. For $\mathrm{GHH}$ preferences, $U(c, n)=$ $u(c-v(n))$, and so $U_{n}=u^{\prime}(c-v(n)) v^{\prime}(n)$ and $U_{c}=u^{\prime}(c-v(n))$ and $U_{n c}=u^{\prime \prime}(c-v(n)) v^{\prime}(n)$ and $U_{c c}=u^{\prime \prime}(c-v(n))$. Hence

$$
\frac{U_{n c}}{U_{n}}=\frac{U_{c c}}{U_{c}}=\frac{u^{\prime \prime}(c-v(n))}{u^{\prime}(c-v(n))}
$$

which shows that $\mathrm{CI}=1$.

\section{A.2 Proof of Proposition 1}

Proof. Log-linearizing (3)-(4) yields a linear system

$$
\left[\begin{array}{cc}
\frac{c U_{c c}}{U_{c}} & \frac{n U_{c n}}{U_{c}} \\
\frac{c U_{n c}}{U_{n}} & \frac{n U_{n n}}{U_{n}}
\end{array}\right]\left[\begin{array}{l}
\hat{c} \\
\hat{n}
\end{array}\right]=\left[\begin{array}{c}
\hat{\lambda} \\
\hat{\lambda}+\hat{w}
\end{array}\right]
$$

The $2 \times 2$ matrix inverse formula implies that the solution is

$$
\left[\begin{array}{l}
\hat{c} \\
\hat{n}
\end{array}\right]=\frac{U_{c} U_{n}}{c n} \frac{1}{U_{c c} U_{n n}-U_{c n}^{2}}\left[\begin{array}{cc}
\frac{n U_{n n}}{U_{n}} & -\frac{U_{c n} n}{U_{c}} \\
\frac{-c U_{n c}}{U_{n}} & \frac{c U_{c c}}{U_{c}}
\end{array}\right]\left[\begin{array}{c}
\hat{\lambda} \\
\hat{\lambda}+\hat{w}
\end{array}\right]
$$

It follows that

$$
\frac{\frac{\partial \log n(\lambda, w)}{\partial \log \lambda}}{\frac{\partial \log n(\lambda, w)}{\partial \log w}}=\frac{\frac{c U_{c c}}{U_{c}}-\frac{c U_{n c}}{U_{n}}}{\frac{c U_{c c}}{U_{c}}}=1-\frac{U_{n c} / U_{n}}{U_{c c} / U_{c}}=1-\mathrm{CI}
$$


and hence, using the definitions of EIS and Frisch in the main text,

$$
\frac{\frac{\partial \log n(\lambda, w)}{\partial \log \lambda}}{\frac{\partial \log c(\lambda, w)}{\partial \log \lambda}}=\frac{\frac{\partial \log n(\lambda, w)}{\partial \log \lambda}}{\frac{\partial \log n(\lambda, w)}{\partial \log w}} \frac{\frac{\partial \log n(\lambda, w)}{\partial \log w}}{\frac{\partial \log c(\lambda, w)}{\partial \log \lambda}}=-\frac{\text { Frisch }}{\text { EIS }}(1-\mathrm{CI}) .
$$

The effect of a one-time transfer is therefore

$$
\frac{\mathrm{MPE}}{\mathrm{MPC}}=\frac{-w \frac{d n}{d T}}{\frac{d c}{d T}}=\frac{-w n \frac{\partial \log n(\lambda, w)}{\partial \log \lambda} \frac{d \log \lambda}{d T}}{c \frac{\partial \log c(\lambda, w)}{\partial \log \lambda} \frac{d \log \lambda}{d T}}=\frac{w n}{c} \frac{\text { Frisch }}{\mathrm{EIS}}(1-\mathrm{CI})
$$

\section{A.3 Proof of Proposition 2}

Proof. Totally differentiating (3) and substituting the linearized market clearing condition $d C_{t}=$ $d Y_{t}-d G_{t}$ (from which the second-order price adjustment cost drops out) gives

$$
U_{c c}\left(d Y_{t}-d G_{t}\right)+U_{c n} d N_{t}=d \lambda_{t}
$$

Now differentiate the production function (10) and use the definition of the labor wedge to get

$$
d N_{t}=\frac{1}{f^{\prime}} d Y_{t}=-(1-\tau) \frac{U_{c}}{U_{n}} d Y_{t}
$$

Combine these two equations to get

$$
d Y_{t}=\frac{1}{1-(1-\tau) \frac{U_{c n} / U_{n}}{U_{c c} / U_{c}}}\left(d G_{t}+\frac{1}{U_{c c}} d \lambda_{t}\right)
$$

where we recognize $\mathrm{CI}=\frac{U_{c n} / U_{n}}{U_{c c} / U_{c}}$ in the denominator.

All that is left is to express $\lambda_{t}$ as a function of the exogenous interest rates. Iterating the Euler equation (8) forward until some $T$ beyond which there are no more shocks, and we have returned to steady state, gives

$$
\begin{aligned}
\lambda_{t} & =\beta^{T-t}\left(\prod_{j=0}^{T-t-1}\left(1+r_{t+j}^{e}\right)\right) U_{c} \\
\log \lambda_{t} & =(T-t) \log \beta+\log U_{c}+\sum_{j=0}^{T-t-1} \log \left(1+r_{t+j}^{e}\right) \\
d \log \lambda_{t} & =\sum_{j=0}^{T-t-1} d \log \left(1+r_{t+j}^{e}\right)
\end{aligned}
$$


and so we have solved for output:

$$
d Y_{t}=\frac{1}{1-(1-\tau) C I}\left[d G_{t}+\frac{U_{c}}{U_{c c}} \sum_{j=0}^{T-t-1} d \log \left(1+r_{t+j}^{e}\right)\right] .
$$

Note that this argument only requires constant real interest rates and the linearized market clearing condition, not our specific sticky-price, flexible-wage general equilibrium. In particular, it works equally well if there are sticky wages instead of, or in addition to, sticky prices, assuming that we directly define $\mathrm{CI}$ as $\frac{U_{c n} / U_{n}}{U_{c c} / U_{c}}$ (since (5) no longer makes sense when households are not on their labor supply curves).

\section{A.4 Properties of GHH-plus preferences}

Recall that GHH-plus preferences are of the form

$$
U(c, n)=\frac{1}{1-\sigma}\left(c-\varphi \alpha \frac{n^{1+v}}{1+v}\right)^{1-\sigma}-\varphi(1-\alpha) \frac{n^{1+v}}{1+v} .
$$

where we assume $\alpha \in[0,1]$ and $\sigma, v, \varphi>0$.

The partials of the utility function are

$$
\begin{aligned}
U_{c} & =\left(c-\varphi \alpha \frac{n^{1+v}}{1+v}\right)^{-\sigma} \\
U_{n} & =-\varphi n^{v}\left[\alpha U_{c}+1-\alpha\right] \\
U_{c c} & =-\sigma\left(c-\varphi \alpha \frac{n^{1+v}}{1+v}\right)^{-\sigma-1} \\
U_{c n} & =-\varphi \alpha n^{v} U_{c c} \\
U_{n n} & =\frac{v}{n} U_{n}-\varphi n^{v} \alpha U_{c n}
\end{aligned}
$$

First, note that this is concave in $(c, n)$. To see this, note that $c-\varphi \alpha \frac{n^{1+v}}{1+v}$ is clearly concave in $(c, n)$, and since the function $\frac{1}{1-\sigma}(\cdot)^{1-\sigma}$ is concave and increasing (for positive arguments), it is concavity-preserving. Finally, $-\varphi(1-\alpha) \frac{n^{1+v}}{1+v}$ is also concave for $\alpha \in[0,1]$, so adding it we get a concave function.

Second, the complementarity index equals

$$
\mathrm{CI}=\frac{U_{c}}{U_{n}} \frac{U_{n c}}{U_{c c}}=\frac{U_{c}}{\varphi n^{v}\left[\alpha U_{c}+1-\alpha\right]} \frac{\varphi \alpha n^{v} U_{c c}}{U_{c c}}=\frac{\alpha U_{c}}{\alpha U_{c}+1-\alpha} .
$$

That is, CI can take any value in $[0,1]$ depending on the choice of $\alpha \in[0,1]$. We recognize the 
special cases from lemma 1: for separable preferences, $\alpha=0=\mathrm{CI}$, and for $\mathrm{GHH}$ preferences, $\alpha=1=\mathrm{CI}$.

Finally, we derive Frisch and EIS. Starting from the labor supply equation (3)(4) we get

$$
\begin{aligned}
w \lambda & =\varphi n^{v}(\alpha \lambda+1-\alpha), \\
n(\lambda, w) & =\left(\frac{w}{\varphi} \frac{\lambda}{\alpha \lambda+1-\alpha}\right)^{\frac{1}{v}}, \\
\log n(\lambda, w) & =\frac{1}{v}[\log w-\log \varphi+\log \lambda-\log (\alpha \lambda+1-\alpha)],
\end{aligned}
$$

which shows that Frisch is still parameterized directly by $v$ :

$$
\text { Frisch }=\frac{\partial \log n(\lambda, w)}{\partial \log w}=\frac{1}{v}
$$

EIS does not have such a simple form, but we can compute it recursively as follows:

$$
\begin{aligned}
\frac{\partial n(\lambda, w)}{\partial \log \lambda} & =\frac{n(\lambda, w)}{v}\left(\frac{1-\alpha}{\alpha \lambda+1-\alpha}\right), \\
\frac{\partial c(\lambda, w)}{\partial \log \lambda} & =\phi \alpha n(\lambda, w)^{v}\left(\frac{\partial n(\lambda, w)}{\partial \log \lambda}\right)-\frac{1}{\sigma} \lambda^{-\frac{1}{\sigma}}, \\
\operatorname{EIS} & =-\frac{\partial \log c(\lambda, w)}{\partial \log \lambda}=-\frac{1}{c(\lambda, w)} \frac{\partial c(\lambda, w)}{\partial \log \lambda} .
\end{aligned}
$$




\section{B Alternative calibrations}
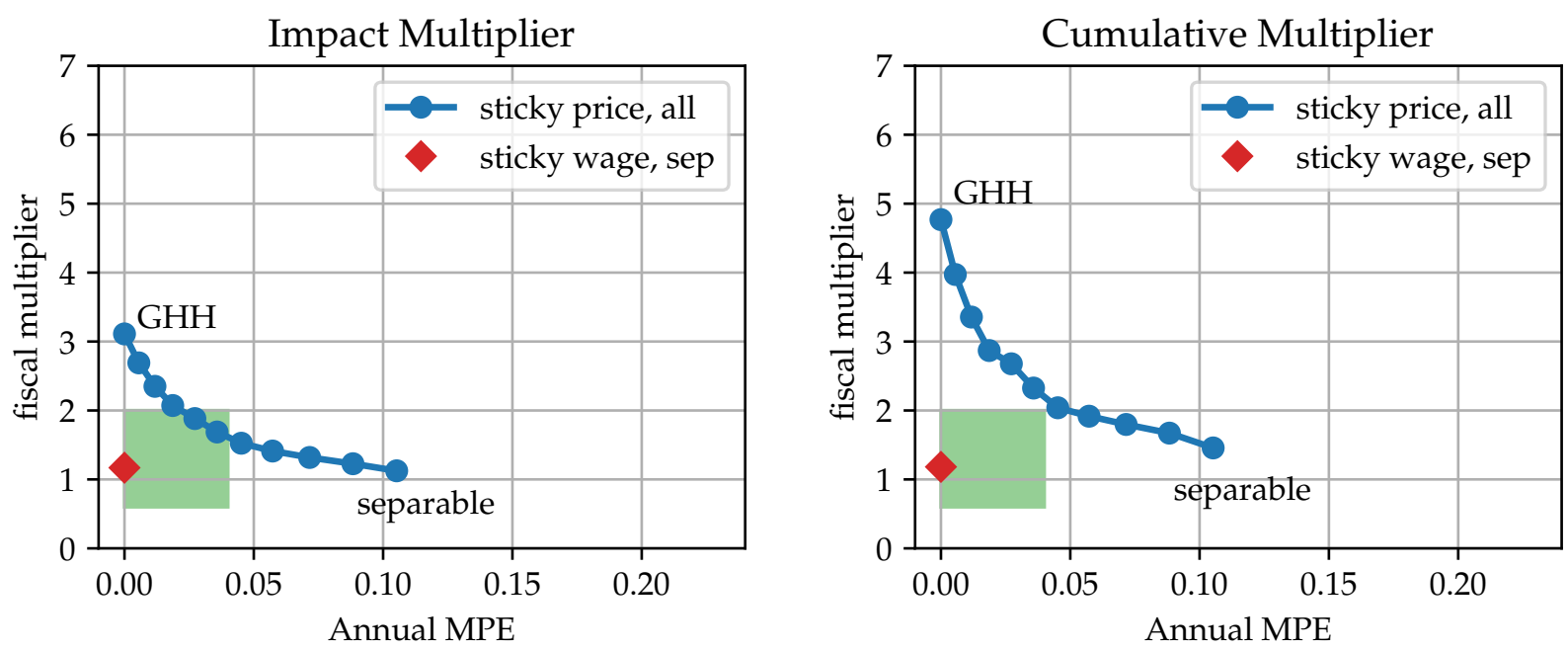

Figure 4: Higher Elasticity of Intertemporal Substitution (1.0)
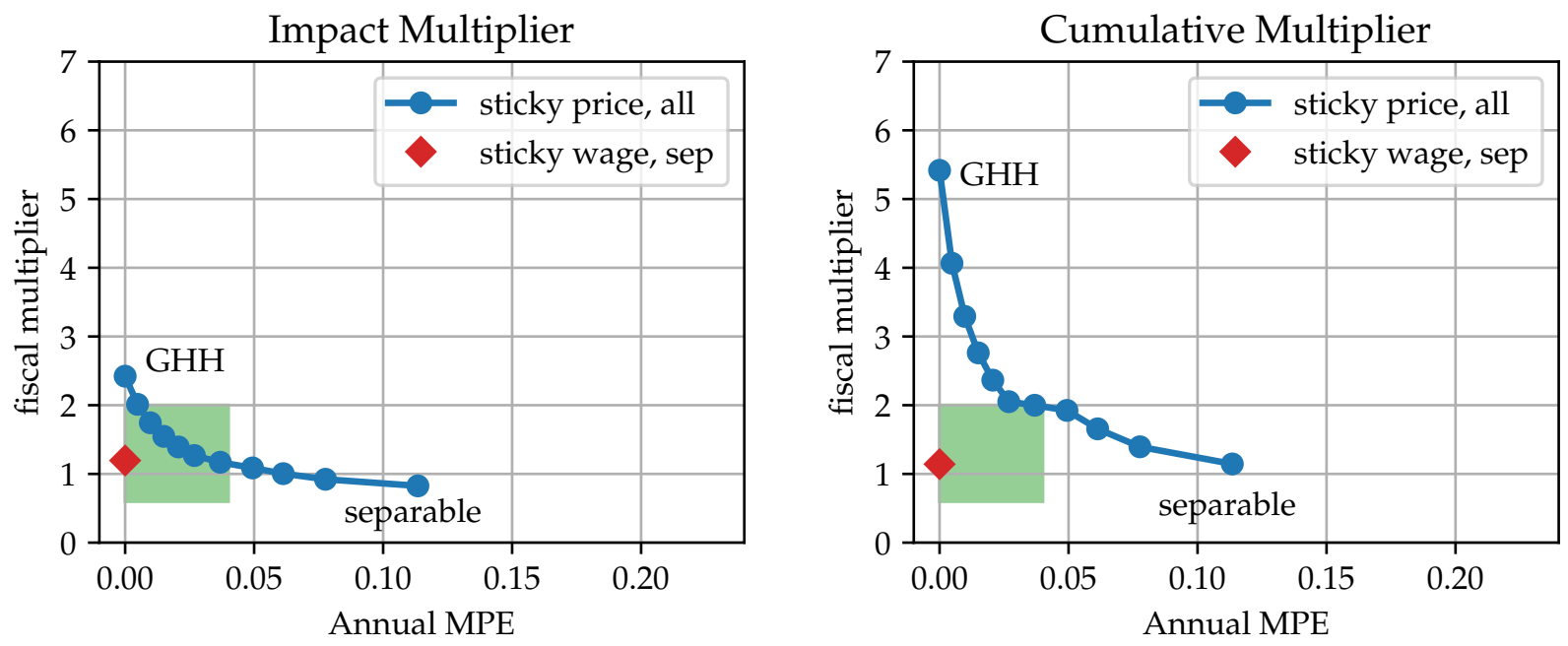

Figure 5: Lower Frisch Elasticity (0.25) 

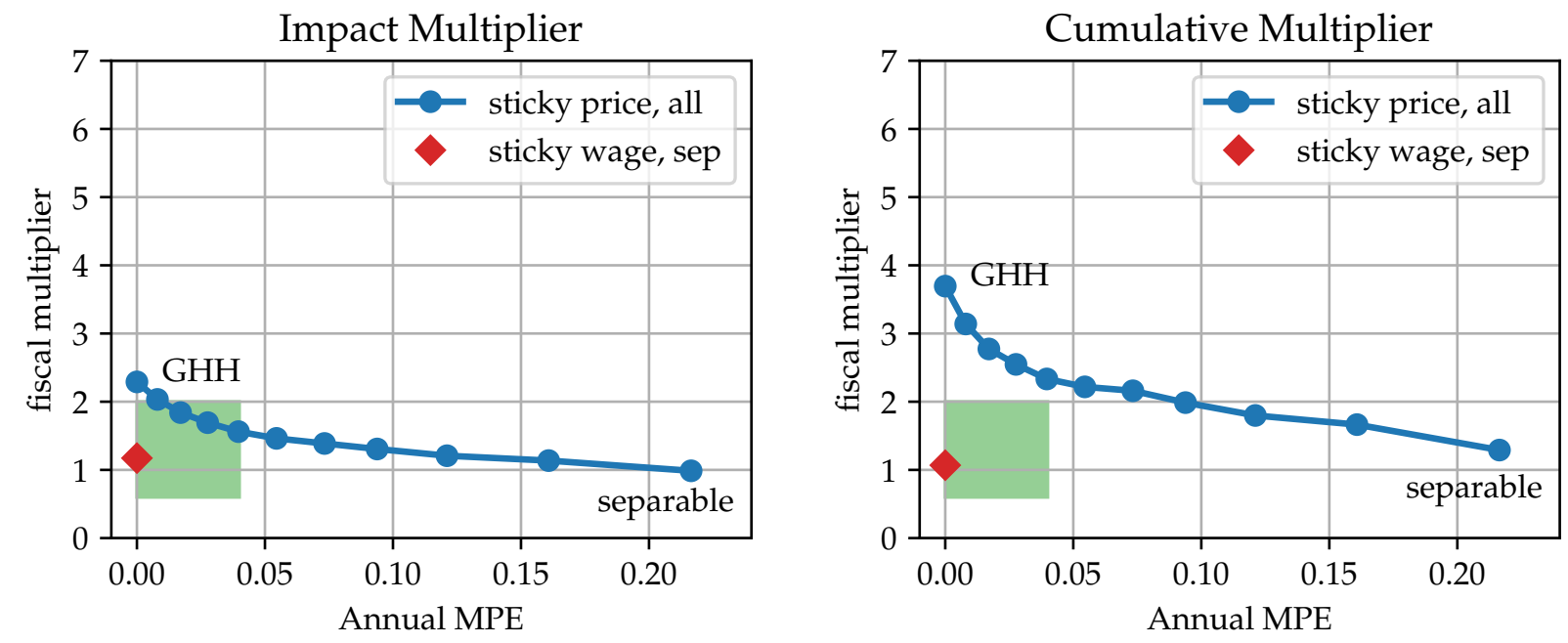

Figure 6: Higher Markup (50\%)
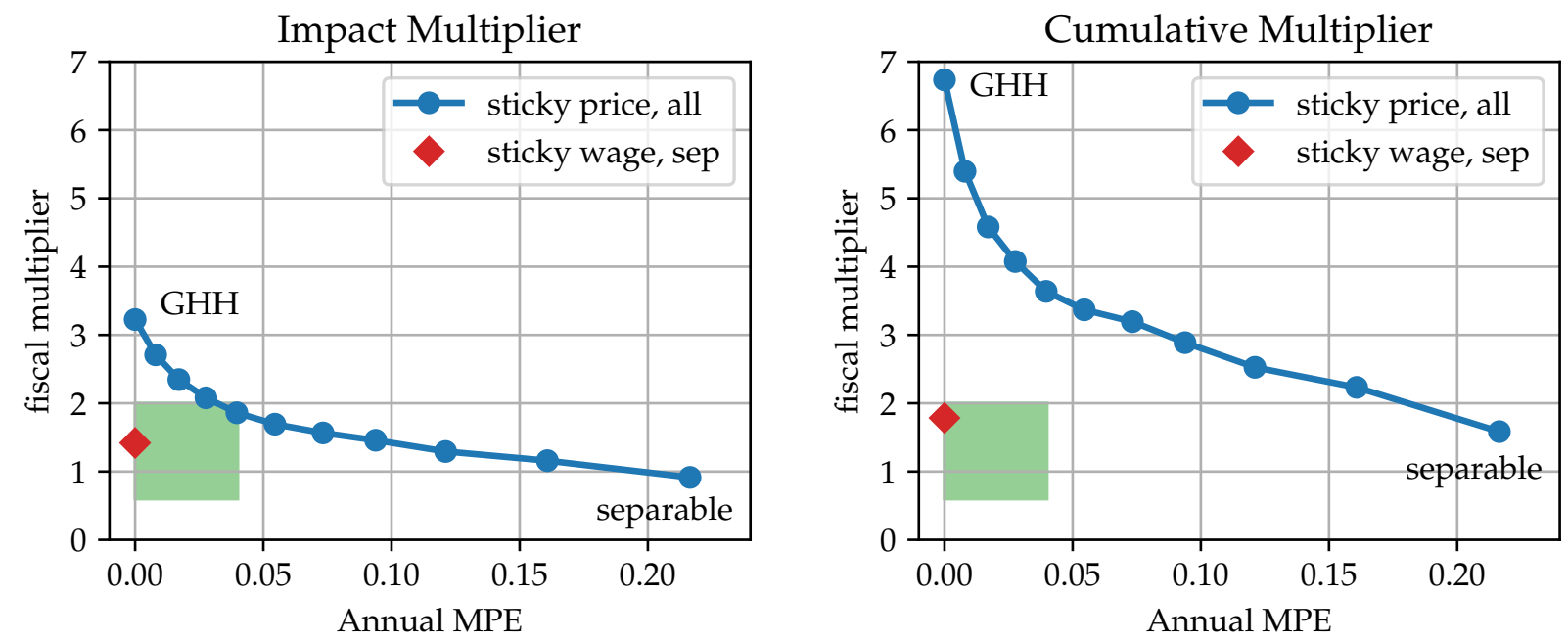

Figure 7: High-Income Households Pay for Government Spending 


\section{Additional impulse responses under separable preferences}

Figure 8 contrasts the set of impulse responses for our sticky-price and sticky-wage models with separable preferences. Interestingly, although the cumulative multipliers are similar in the two cases, the dynamics are quite different: the consumption response in the sticky-price case starts negative and then becomes persistently positive, while the consumption response in the stickywage case more closely mirrors the trajectory of government spending.

The non-monotonic aggregate consumption response reflects some of the peculiar properties of the sticky-price model. As the middle two rows of figure 8 show, this model features both a very large decline in equity prices and a large increase in wages. Since patient households own most of the equity, they suffer a negative wealth effect, and as figure 9 shows, cut their consumption while increasing hours. Impatient households, on the other hand, experience a large positive wealth effect from wages, and increase their consumption while cutting hours. These two very large and opposite-signed effects on both consumption and hours-which seem empirically implausible-net out to a much smaller cumulative increase in consumption. (Note that although these extremely heterogeneous responses show up in our model in patient vs. impatient agents, all that is really needed is wealth heterogeneity.) The consumption impulse response starts negative because the MPC out of the large date- 0 decline in equity wealth initially dominates.

In contrast, the sticky-price impulse responses in figure 10 display a much more plausible degree of heterogeneity. 

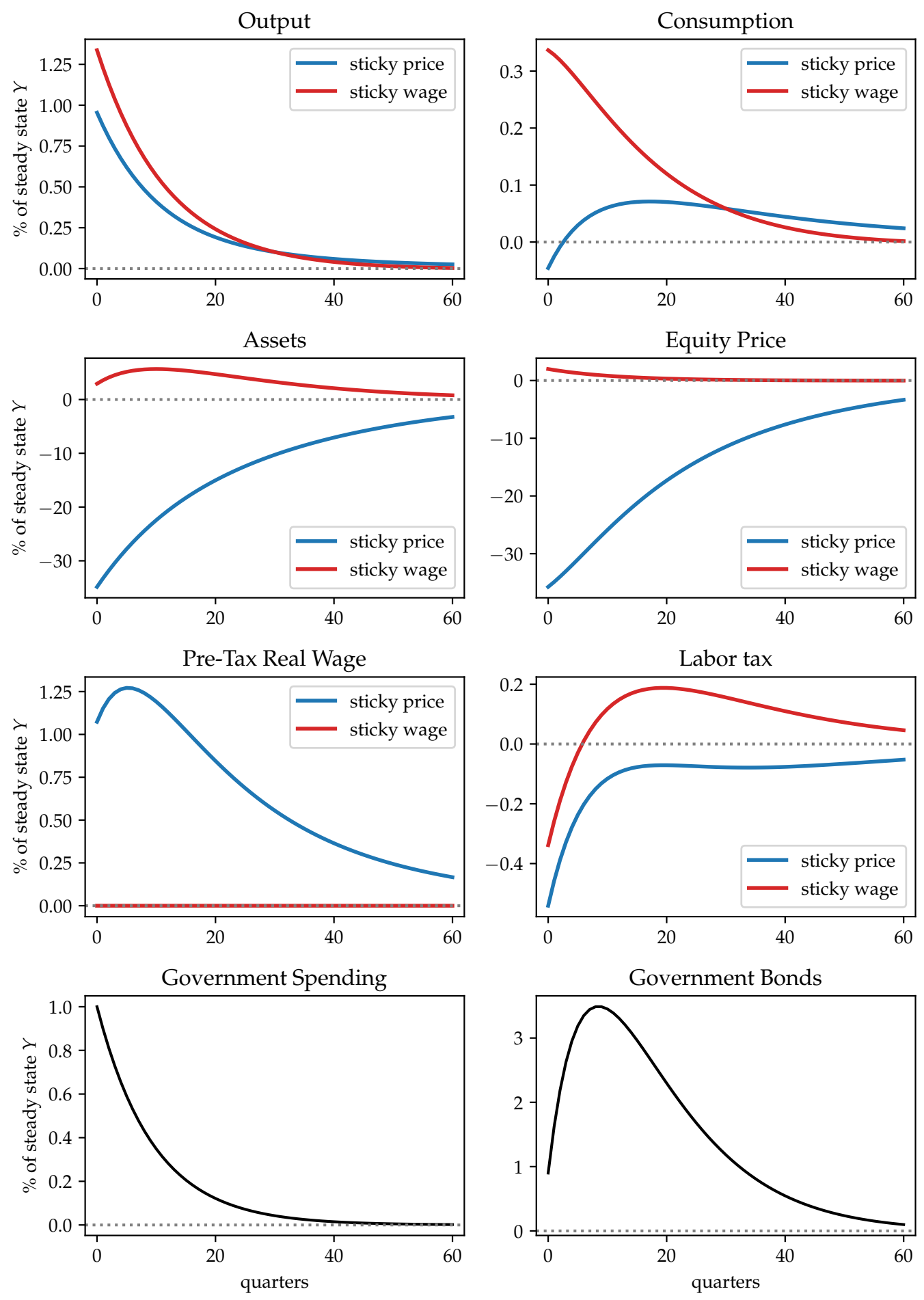

Figure 8: Impulse Responses with Separable Preferences 

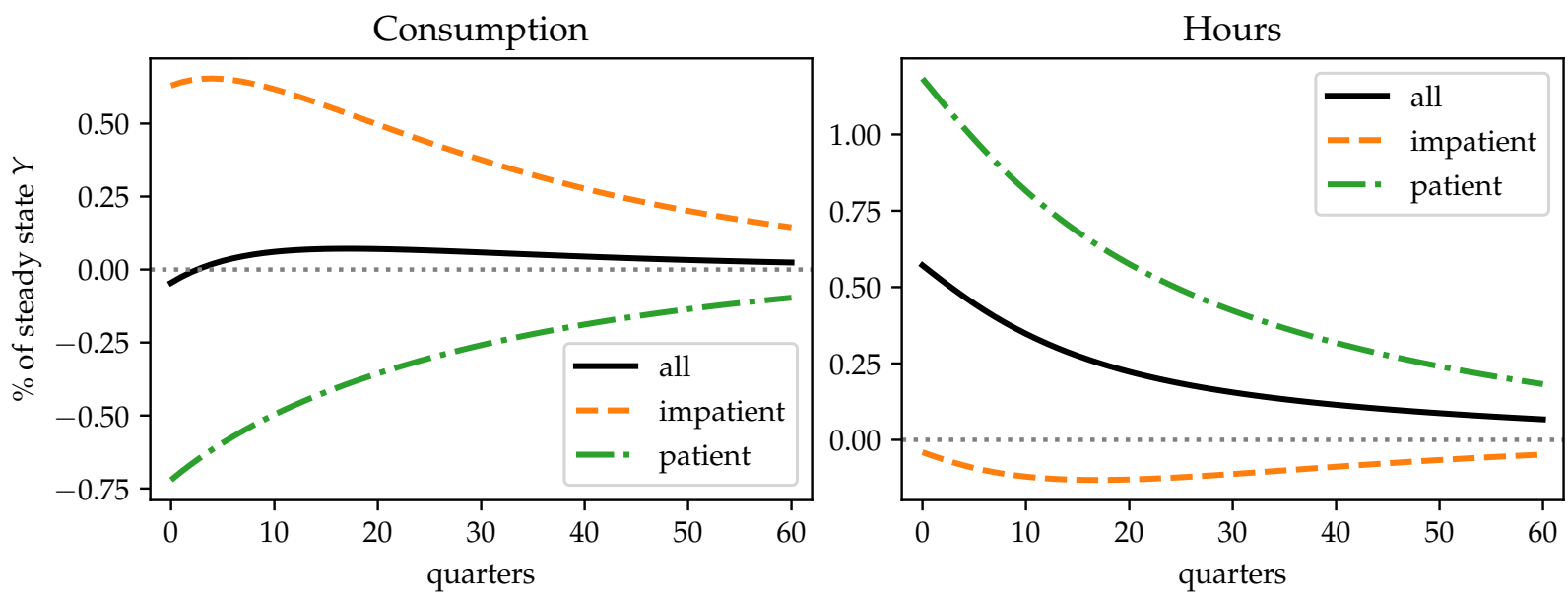

Figure 9: Disaggregated Responses in Sticky-Price Model with Separable Preferences
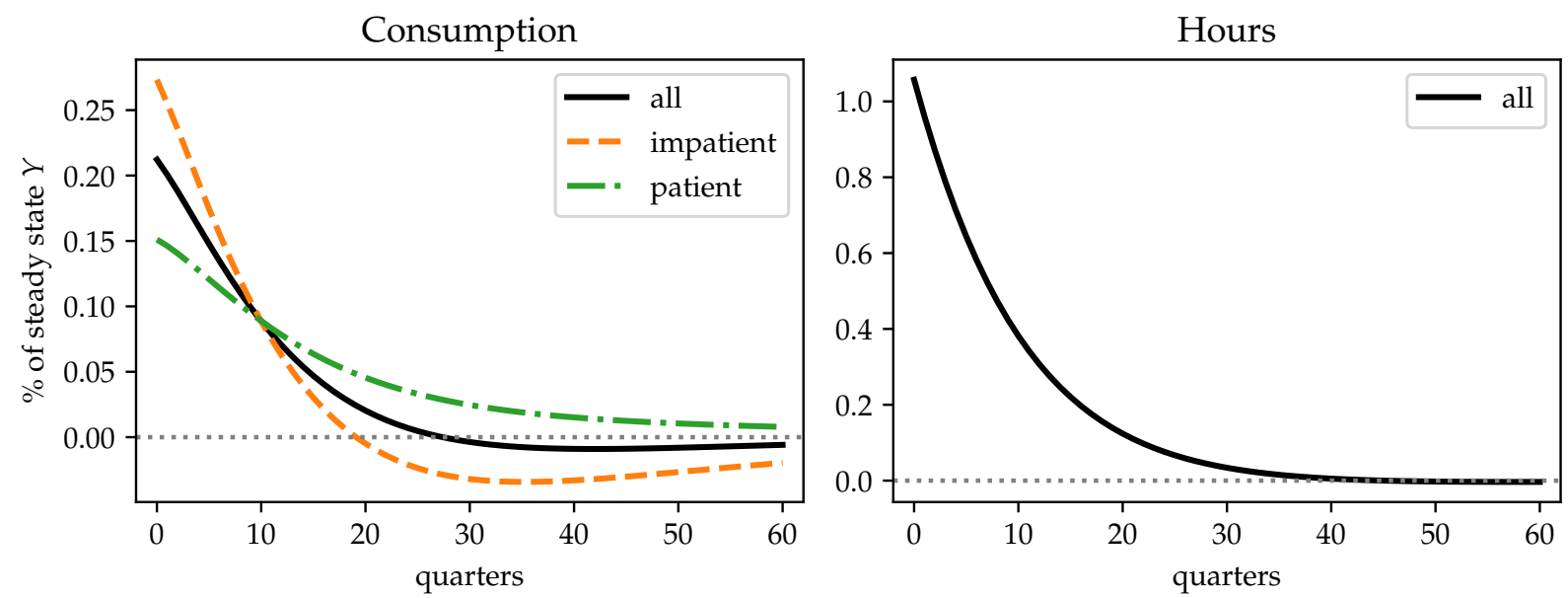

Figure 10: Disaggregated Responses in Sticky-Wage Model with Separable Preferences 


\section{Summary of model equations}

\section{D.1 Sticky-price HANK}

This is the benchmark model we use to generate the blue circles in figure 2 .

- Households:

The Bellman equation

$$
\begin{aligned}
V_{t}\left(e_{i t}, a_{i t-1}\right)= & \max _{c_{i t}, n_{i t}, a_{i t}} \frac{1}{1-\sigma}\left(c_{i t}-\varphi \alpha \frac{n_{i t}^{1+v}}{1+v}\right)^{1-\sigma}-\varphi(1-\alpha) \frac{n_{i t}^{1+v}}{1+v}+\beta \mathbb{E}_{t}\left[V_{t+1}\left(e_{i t+1}, a_{i t}\right)\right] \\
\text { s.t. } & c_{i t}+a_{i t}=\left(1+r_{t}\right) a_{i t-1}+\left(1-\tau_{t}^{w}\right) w_{t} e_{i t} n_{i t}+T_{t} \\
& a_{i t} \geq \underline{a}
\end{aligned}
$$

gives aggregate consumption, asset demand, and labor supply:

$$
\begin{aligned}
& C_{t}=\mathcal{C}_{t}\left(\left\{r_{s}, r_{s}^{e}, \tau_{s}^{w}, w_{s}, T_{s}\right\}\right)=\int c_{i t} d i \\
& A_{t}=\mathcal{A}_{t}\left(\left\{r_{s}, r_{s}^{e}, \tau_{s}^{w}, w_{s}, T_{s}\right\}\right)=\int a_{i t} d i \\
& N_{t}=\mathcal{N}_{t}\left(\left\{r_{s}, r_{s}^{e}, \tau_{s}^{w}, w_{s}, T_{s}\right\}\right)=\int e_{i t} n_{i t} d i
\end{aligned}
$$

- Production:

$$
Y_{t}=Z N_{t}-F
$$

- Phillips curve:

$$
\log \left(1+\pi_{t}\right)=\kappa_{p}\left(\frac{w_{t}}{Z}-\frac{\epsilon_{p}-1}{\epsilon_{p}}\right)+\frac{1}{1+r_{t}^{e}} \frac{Y_{t+1}}{Y_{t}} \log \left(1+\pi_{t+1}\right)
$$

- Dividends:

$$
d_{t}=Y_{t}-w_{t} N_{t}-\frac{\epsilon_{p}}{2 \kappa_{p}} \log \left(1+\pi_{t}\right)^{2} Y_{t}
$$

- Equity price:

$$
p_{t}=\frac{d_{t+1}+p_{t+1}}{1+r_{t}^{e}}
$$

- Realized return on portfolio:

$$
1+r_{t}=\frac{p_{t-1}}{p_{t-1}+B_{t-1}} \frac{d_{t}+p_{t}}{p_{t-1}}+\frac{B_{t-1}}{p_{t-1}+B_{t-1}}\left(1+r_{t-1}^{e}\right)
$$


- Monetary policy:

$$
r_{t}^{e} \equiv r_{S S}
$$

- Government budget:

$$
B_{t}+\tau_{t}^{w} w_{t} N_{t}=\left(1+r_{t-1}^{e}\right) B_{t-1}+G_{t}+T_{t} .
$$

- Public debt policy:

$$
B_{t}-B_{s s}=\rho_{B}\left(B_{t-1}-B_{s s}+G_{t}-G_{s s}\right)
$$

- Baseline tax policy:

$$
T_{t}=T
$$

- Market clearing:

$$
\begin{aligned}
& Y_{t}=C_{t}+G_{t}+\frac{\epsilon_{p}}{2 \kappa_{p}} \log \left(1+\pi_{t}\right)^{2} Y_{t} \\
& A_{t}=B_{t}+p_{t}
\end{aligned}
$$

\section{D.2 Sticky-wage HANK}

This is the benchmark model we use to generate the dark red diamond on figure 2. Here we list only the equations that differ from the sticky-price model in appendix D.1.

- Households:

The Bellman equation

$$
\begin{aligned}
V_{t}\left(e_{i t}, a_{i t-1}\right)= & \max _{c_{i t}, a_{i t}} \frac{c_{i t}^{1-\sigma}}{1-\sigma}+\beta \mathbb{E}_{t}\left[V_{t+1}\left(e_{i t+1}, a_{i t}\right)\right] \\
\text { s.t. } & c_{i t}+a_{i t}=\left(1+r_{t}\right) a_{i t-1}+\left(1-\tau_{t}^{w}\right) w_{t} N_{t} e_{i t}+T_{t} \\
& a_{i t} \geq \underline{a}
\end{aligned}
$$

gives aggregate consumption, asset demand, and marginal utility of consumption:

$$
\begin{aligned}
& C_{t}=\mathcal{C}_{t}\left(\left\{r_{s}, r_{s}^{e}, \tau_{s}, w_{s}, N_{s}, T_{s}\right\}\right)=\int c_{i t} d i, \\
& A_{t}=\mathcal{A}_{t}\left(\left\{r_{s}, r_{s}^{e}, \tau_{s}, w_{s}, N_{s}, T_{s}\right\}\right)=\int a_{i t} d i, \\
& U_{t}^{c}=\mathcal{U}_{t}\left(\left\{r_{s}, r_{s}^{e}, \tau_{s}, w_{s}, N_{s}, T_{s}\right\}\right)=\int e_{i t} c_{i t}^{-\sigma} d i .
\end{aligned}
$$

- Phillips curve: replace (36) with

$$
\log \left(1+\pi_{t}\right)=\kappa_{w}\left[\varphi N_{t}^{1+v}-\left(1-\tau_{t}^{w}\right) w_{t} N_{t}\left(\frac{\epsilon_{w}-1}{\epsilon_{w}}\right) U_{t}^{c}\right]+\beta \log \left(1+\pi_{t+1}\right)
$$


- Price setting:

$$
\frac{w_{t}}{Z}=\frac{\epsilon_{p}-1}{\epsilon_{p}}
$$

- Dividends: replace (37) with

$$
d_{t}=Y_{t}-w_{t} N_{t}
$$

- Market clearing: replace (44) with

$$
Y_{t}=C_{t}+G_{t}
$$

\section{D.3 Extensions}

Here we briefly describe the models used to construct table 2.

- Taylor rule: replace (40) with

$$
\begin{aligned}
i_{t} & =r_{s s}+\phi \pi_{t} \\
1+r_{t}^{e} & =\frac{1+i_{t}}{1+\pi_{t+1}}
\end{aligned}
$$

- Nominal peg: replace (53) with

$$
i_{t}= \begin{cases}r_{s S} & \text { for } t=0,1, \ldots 11 \\ r_{s S}+\phi \pi_{t} & \text { for } t \geq 12\end{cases}
$$

\section{E Computational appendix}

Endogenous gridpoints method for GHH-plus preferences. Recall that GHH-plus preferences are

$$
U(c, n)=\frac{1}{1-\sigma}\left(c-\varphi \alpha \frac{n^{1+v}}{1+v}\right)^{1-\sigma}-\varphi(1-\alpha) \frac{n^{1+v}}{1+v}
$$

and the first order conditions are

$$
\begin{aligned}
U_{c}\left(c_{i t}, n_{i t}\right) & =\lambda_{i t}+\beta\left(1+r_{t}^{e}\right) \mathbb{E}_{t} U_{c}\left(c_{i t+1}, n_{i t+1}\right) \\
-U_{n}\left(c_{i t}, n_{i t}\right) & =w_{t}\left(e_{i t}\right) U_{c}\left(c_{i t}, n_{i t}\right) \\
\lambda_{i t}\left(a_{i t}-\underline{a}\right) & =0 \\
c_{i t}+a_{i t} & =\left(1+r_{t}\right) a_{i t-1}+w_{t}\left(e_{i t}\right) n_{i t}+T_{t}
\end{aligned}
$$

The core of the algorithm is a backward iteration of $U_{c}$ on a discrete grid $\mathcal{G}=(e, a)$. Let $\Pi$ denote the Markov transition matrix of the income state $e$. In this section only, we're going to use primes to refer to the next period. Thus, $U_{c}^{\prime}$ denotes marginal utility next period and $\left(e^{\prime}, a^{\prime}\right)$ refers to the grid next period. 
1. Initial guess $U_{c}^{\prime}\left(e^{\prime}, a^{\prime}\right)$, marginal utility tomorrow on tomorrow's grid.

2. $e^{\prime} \rightarrow e$ For unconstrained agents (56) implies that

$$
U_{c}\left(e, a^{\prime}\right)=\beta\left(1+r^{e}\right) \Pi U_{c}^{\prime}\left(e^{\prime}, a^{\prime}\right) .
$$

Then use the labor supply equation (57) to obtain

$$
\begin{aligned}
& n\left(e, a^{\prime}\right)=\left(\frac{w(e)}{\varphi} \frac{U_{c}\left(e, a^{\prime}\right)}{\alpha U_{c}\left(e, a^{\prime}\right)+1-\alpha}\right)^{\frac{1}{v}}, \\
& c\left(e, a^{\prime}\right)=U_{c}\left(e, a^{\prime}\right)^{-\sigma}+\varphi \alpha \frac{n\left(e, a^{\prime}\right)^{1+v}}{1+v} .
\end{aligned}
$$

3. $a^{\prime} \rightarrow a$ the budget constraint (59) defines a mapping $a\left(e, a^{\prime}\right)$ :

$$
c\left(e, a^{\prime}\right)+a^{\prime}-w(e) n\left(e, a^{\prime}\right)=(1+r) a+T
$$

which we can use to obtain $c(e, a)$ and $n(e, a)$ by linear interpolation. Then

$$
a^{\prime}(e, a)=(1+r) a+T+w(e) n(e, a)-c(e, a)
$$

4. Borrowing constraint Let $\mathcal{B} \subset \mathcal{G}$ be the set of gridpoints where $a^{\prime}(e, a)<\underline{a}$. At these points only, $c(e, a)$ and $n(e, a)$ obtained in step 3 are invalid. The right values solve

$$
c(e, a), n(e, a)=\underset{c, n}{\arg \max } U(c, n) \quad \text { s.t. } c=(1+r) a+w(e) n+T
$$

a static optimization problem that's independent of the current guess of $U_{c}^{\prime}$ and thus can be precomputed when solving for the steady state.

5. Update guess

$$
U_{c}(e, a)=\left(c(e, a)-\varphi \alpha \frac{n(e, a)^{1+v}}{1+v}\right)^{-\sigma} .
$$

General equilibrium. We solve for impulse responses directly in sequence space as explained in Auclert, Bardóczy, Rognlie and Straub (2020) using the toolkit published alongside that paper, available at https://github.com/shade-econ/sequence-jacobian. Here we sketch the method for the benchmark sticky-price model.

There are 14 numbered equilibrium conditions in appendix D.1. Either goods market clearing or asset market clearing is redundant by Walras's law. That is, the we have a system of $13 \times T$ nonlinear equations that characterize the time paths—truncated at some large $T^{26}$ —of endoge-

\footnotetext{
${ }^{26}$ The choice of the truncation horizon is dictated by how long it takes for the economy to approximately return to the steady state. We found that $T=200$ is sufficient in all cases we consider in the paper.
} 
nous variables $\mathbf{U}=\left\{C_{t}, A_{t}, N_{t}, r_{t}, r_{t}^{e}, \tau_{t}^{w}, w_{t}, T_{t}, Y_{t}, \pi_{t}, d_{t}, p_{t}, B_{t}\right\}_{t=0}^{T-1}$ conditional on a path of the exogenous variable $\mathbf{G}=\left\{G_{t}\right\}_{t=0}^{T-1}$. We solve the system $\mathbf{H}(\mathbf{U}, \mathbf{G})=0$ in two steps. First, we reduce the set of unknowns to $\left\{\pi_{t}, w_{t}, N_{t}\right\}_{t=0}^{T-1}$ by taking advantage of the limited dependency among the equilibrium conditions. Second, we compute the Jacobians of $\mathbf{H}$ at the steady state. The Jacobians fully characterize aggregate impulse responses around the steady state.

\section{F Additional results}

\section{F.1 Proof of "Ricardian equivalence" in the sticky-price model}

We will prove a special case of Ricardian equivalence that applies to first order in the model. The key idea is that in equilibrium, in whatever period the government raises taxes to pay for spending, firms will raise pretax wages by the same amount, so that the after-tax wage is unchanged, and indeed consumption, labor, and assets are unchanged for every household in every period.

For this to happen, it is essential that firm equity is discounted using the same interest rate paid on government debt. When the government decreases the debt from $t+1$ onward by raising taxes at time $t$, there is an exactly offsetting increase in the valuation of firms, because the loss from raising wages at time $t$ is no longer included in the time $t+1$ equity price.

Proof. First, note that ex-post return $r_{t}$ is fixed in all periods except 0 :

$$
1+r_{t}= \begin{cases}\frac{p_{s s}}{p_{s s}+B_{s S}} \frac{d_{0}+p_{0}}{p_{s s}}+\frac{B_{s s}}{p_{s s}+B_{s s}}\left(1+r_{s s}\right) & \text { for } t=0 \\ 1+r_{s S} & \text { for } t \geq 1\end{cases}
$$

Therefore, the only endogenous inputs to the households' problem are the path of after-tax wages and the cum dividend price of equity in period 0 . In particular, the aggregate labor supply function can be written as

$$
N_{t}=\mathcal{N}_{t}\left(\left\{\left(1-\tau_{s}^{w}\right) w_{s}\right\}_{s \geq 0}, d_{0}+p_{0}\right) .
$$

Second, iterating the pricing equation (38) forward and using the definition of dividends (37) (ignoring second-order adjustment costs) and the production function (35) yields

$$
\begin{aligned}
d_{0}+p_{0} & =\sum_{t=0}^{\infty}\left(1+r_{s s}\right)^{-t} d_{t} \\
& =\sum_{t=0}^{\infty}\left(1+r_{s s}\right)^{-t}\left(Y_{t}-w_{t} N_{t}\right) \\
& =\sum_{t=0}^{\infty}\left(1+r_{s s}\right)^{-t}\left[\left(Z-w_{t}\right) N_{t}-F\right],
\end{aligned}
$$

which shows that ex-post return depends only on the present values of $\left\{N_{t}\right\}_{t \geq 0}$ and $\left\{w_{t} N_{t}\right\}_{t \geq 0}$. 
Third, iterating the government budget constraint (41) forward yields

$$
\left(1+r_{S S}\right) B_{-1}+\sum_{t=0}^{\infty}\left(1+r_{S S}\right)^{-t}\left(G_{t}+T\right)=\sum_{t=0}^{\infty}\left(1+r_{S S}\right)^{-t} \tau_{t}^{w} w_{t} N_{t}
$$

Let the sequences $\left\{\tau_{t}^{w, *}, N_{t}^{*}, w_{t}^{*}\right\}_{t \geq 0}$ be part of an equilibrium. Now consider an alternative path of taxes that is part of an equilibrium $\left\{\tau_{t}^{w}, N_{t}, w_{t}\right\}_{t \geq 0}$. We're going to guess and verify that $N_{t}=N_{t}^{*}$ and $\left(1-\tau_{t}^{w}\right) w_{t}=\left(1-\tau_{t}^{w, *}\right) w_{t}^{*}$ for all $t \geq 0$. That is, the pre-tax wage offsets any change in taxes and the real outcomes are the same.

The conjecture immediately implies that

$$
\left(1-\tau_{t}^{w}\right) w_{t} N_{t}=\left(1-\tau_{t}^{w, *}\right) w_{t}^{*} N_{t}^{*}, \quad \forall t \geq 0 .
$$

Now take present discounted values and use the fact that both allocations satisfy (62) to see that the present value of wage costs is the same:

$$
\begin{aligned}
\sum_{t=0}^{\infty}\left(1+r_{s S}\right)^{-t}\left(1-\tau_{t}^{w}\right) w_{t} N_{t} & =\sum_{t=0}^{\infty}\left(1+r_{s S}\right)^{-t}\left(1-\tau_{t}^{w, *}\right) w_{t}^{*} N_{t}^{*} \\
\sum_{t=0}^{\infty}\left(1+r_{S S}\right)^{-t} w_{t} N_{t} & =\sum_{t=0}^{\infty}\left(1+r_{s S}\right)^{-t} w_{t}^{*} N_{t}^{*}
\end{aligned}
$$

It follows, by the conjecture $N_{t}=N_{t}^{*}$, that the present value of pre-tax wages is also the same:

$$
\sum_{t=0}^{\infty}\left(1+r_{s s}\right)^{-t} w_{t}=\sum_{t=0}^{\infty}\left(1+r_{s s}\right)^{-t} w_{t}^{*}
$$

It follows from (61) that

$$
p_{0}+d_{0}=p_{0}^{*}+d_{0}^{*}
$$

We have shown that all inputs of the aggregate labor supply function are the same in both allocations, hence verified $N_{t}=N_{t}^{*}$. It follows that $Y_{t}=Y_{t}^{*}$ and $C_{t}=C_{t}^{*}$ and $A_{t}=A_{t}^{*}$. This means that goods market clearing holds period by period, up to the price-adjustment cost which is a second order term. Asset market clearing then follows from Walras's law. This means that $B_{t}+p_{t}=B_{t}^{*}+p_{t}^{*}$ for all $t$ even though $B_{t} \neq B_{t}^{*}$ and $p_{t} \neq p_{t}^{*}$ in general.

\section{F.2 Derivation of the wage Phillips curve}

Here, we adapt the derivation of the wage Phillips curve from Auclert et al. (2018) to take into account the specification of the tax system in (2). Although our calibration features separable preferences, here we allow for general nonseparable preferences.

Let household $i$ supply a continuum of labor services $n_{i k t}$ which are imperfect substitutes. We assume that there is a union for each type of labor $k$. These unions set a common wage per efficiency unit $w_{k t}$, and their members have to supply labor demanded at that wage. Labor demand 
has the usual isoelastic form with elasticity $\epsilon_{w}$. The unions' objective is to maximize the average welfare of their members, taking their consumption choice as given.

At any time $t$, union $k$ sets its real wage $w_{k t}$ to maximize

$$
\sum_{\tau \geq 0} \beta^{t+\tau}\left[\int U\left(c_{i t+\tau}, n_{i t+\tau}\right) d i-\frac{\epsilon_{w}}{2 \kappa_{w}} \log \left(\frac{w_{k t+\tau}}{w_{k t+\tau-1}}\left(1+\pi_{t}\right)\right)^{2}\right]
$$

subject to the demand curve

$$
N_{k t}=\left(\frac{w_{k t}}{w_{t}}\right)^{-\epsilon_{w}} N_{t}
$$

Using symmetry as appropriate, the FOC may be written as

$$
0=\int U_{c}\left(c_{i t}, n_{i t}\right) \frac{\partial c_{i t}}{\partial w_{k t}}+U_{n}\left(c_{i t}, n_{i t}\right) \frac{\partial n_{i t}}{\partial w_{k t}} d i-\frac{\epsilon_{w}}{\kappa_{w}} \frac{\log \left(1+\pi_{t}^{w}\right)}{w_{t}}+\frac{\beta \epsilon_{w}}{\kappa_{w}} \frac{\log \left(1+\pi_{t+1}^{w}\right)}{w_{t}} .
$$

Next, we express the partial derivatives of consumption and labor. Household $i$ 's total hours are

$$
n_{i t}=\int N_{k t} d k=\int\left(\frac{w_{k t}}{w_{t}}\right)^{-\epsilon_{w}} N_{t} d k
$$

and therefore

$$
\frac{\partial n_{i t}}{\partial w_{k t}}=-\epsilon_{w} \int \frac{N_{k t}}{w_{k t}} d k=-\epsilon_{w} \frac{N_{t}}{w_{t}}
$$

By the envelope theorem, the marginal effect on consumption is equal to the marginal effect on income. Household income is

$$
\begin{aligned}
z_{i t} & =\left(1-\tau_{t}^{w}\right) w_{t} e_{i t} n_{i t}+T_{t} \\
& =\left(1-\tau_{t}^{w}\right) e_{i t} \int w_{k t} n_{i k t} d k+T_{t} \\
& =\left(1-\tau_{t}^{w}\right) e_{i t} N_{t} \int w_{k t}\left(\frac{w_{k t}}{w_{t}}\right)^{-\epsilon_{w}} d k+T_{t}
\end{aligned}
$$

and thus

$$
\frac{\partial z_{i t}}{\partial w_{k t}}=N_{t}\left(1-\epsilon_{w}\right)\left(1-\tau_{t}^{w}\right) e_{i t}
$$

Substituting (65) and (66) into the FOC gives

$$
\begin{aligned}
\log \left(1+\pi_{t}^{w}\right)=\kappa_{w}[ & N_{t} \int-U_{n}\left(c_{i t}, n_{i t}\right) d i \\
& \left.\quad-w_{t} N_{t}\left(1-\tau_{t}^{w}\right)\left(\frac{\epsilon_{w}-1}{\epsilon_{w}}\right) \int e_{i t} U_{c}\left(c_{i t}, n_{i t}\right) d i\right] \\
& +\beta \log \left(1+\pi_{t+1}^{w}\right)
\end{aligned}
$$

This means that household heterogeneity affects wage setting via two cross-sectional moments: the average marginal disutility of labor and the productivity-weighted average marginal utility of 
consumption. To get a more compact expression, let's define

$$
\begin{aligned}
& U_{t}^{n}=\int-U_{n}\left(c_{i t}, n_{i t}\right) d i, \\
& U_{t}^{c}=\int e_{i t} U_{c}\left(c_{i t}, n_{i t}\right) d i .
\end{aligned}
$$

We can then write the wage Phillips curve as

$$
\log \left(1+\pi_{t}^{w}\right)=\kappa_{w}\left[N_{t} U_{t}^{n}-w_{t} N_{t}\left(1-\tau_{t}^{w}\right)\left(\frac{\epsilon_{w}-1}{\epsilon_{w}}\right) U_{t}^{c}\right]+\beta \log \left(1+\pi_{t+1}^{w}\right) .
$$

which is equation (25) in the main text. 